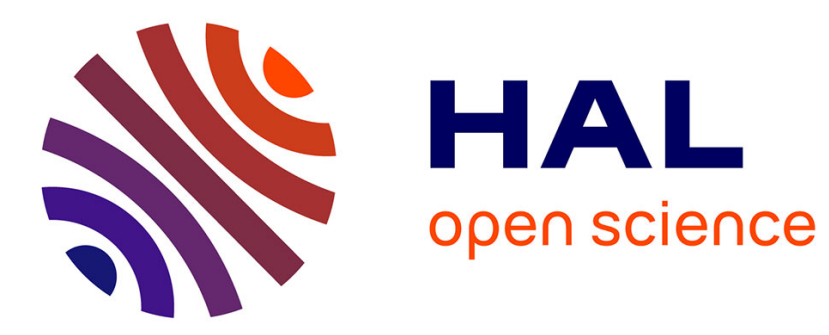

\title{
Innate immunity in C. elegans
}

Céline Martineau, Natalia Kirienko, Nathalie Pujol

\section{To cite this version:}

Céline Martineau, Natalia Kirienko, Nathalie Pujol. Innate immunity in C. elegans. Nematode Models of Development and Disease, 144, Elsevier, pp.309-351, 2021, Current Topics in Developmental Biology, 10.1016/bs.ctdb.2020.12.007 . hal-03373535

\section{HAL Id: hal-03373535 \\ https://hal.science/hal-03373535}

Submitted on 12 Oct 2021

HAL is a multi-disciplinary open access archive for the deposit and dissemination of scientific research documents, whether they are published or not. The documents may come from teaching and research institutions in France or abroad, or from public or private research centers.
L'archive ouverte pluridisciplinaire HAL, est destinée au dépôt et à la diffusion de documents scientifiques de niveau recherche, publiés ou non, émanant des établissements d'enseignement et de recherche français ou étrangers, des laboratoires publics ou privés. 


\title{
INNATE IMMUNITY IN C. ELEGANS
}

\author{
Celine N. MARTINEAU ${ }^{1, *}$, Natalia V. KIRIENKO ${ }^{2, *}{ }^{*}$, , Nathalie PUJOL ${ }^{1, \S}$ \\ ${ }^{1}$ Aix Marseille Université, Inserm, CNRS, CIML, Turing Centre for Living Systems, Marseille, \\ France \\ ${ }^{2}$ Department of BioSciences, Rice University, Houston TX, United States of America. \\ ${ }^{*}$ contributed equally \\ § corresponding authors kirienko@rice.edu \& pujol@ciml.univ-mrs.fr
}

\section{Abstract}

In its natural habitat, $C$. elegans encounters a wide variety of microbes, including food, commensals and pathogens. To be able to survive long enough to reproduce, $C$. elegans has developed a complex array of responses to pathogens. These activities are coordinated on scales that range from individual organelles to the entire organism. Often, the response is triggered within cells, by detection of infection-induced damage, mainly in the intestine or epidermis. $C$. elegans has, however, a capacity for cell non-autonomous regulation of these responses. This frequently involves the nervous system, integrating pathogen recognition, altering host biology and governing avoidance behaviour. Although there are significant differences with the immune system of mammals, some mechanisms used to limit pathogenesis show remarkable phylogenetic conservation. The past twenty years have witnessed an explosion of host-pathogen interaction studies using $C$. elegans as a model. This review will discuss the broad themes that have emerged and highlight areas that remain to be fully explored.

\section{Natural environment and microbiota}

Caenorhabditis elegans is a small free-living nematode found worldwide, predominately in humid, temperate areas where it can feed on the bacteria that proliferate on decaying vegetation (Schulenburg and Félix, 2017). Its natural environment comprises a complex community of microbes, including bacteria, fungi and viruses, including many parasitic species. The effect of environmental microbes on worm fitness can be beneficial, detrimental or mixed (Khan et al., 2018). And as the same microorganism can sometime be either beneficial or detrimental depending on the environmental conditions or the genotype of the host (Gravato-Nobre et al., 2020; Zarate-Potes et al., 2020), we will use the terms of "pathogen" or "commensal" for a given microbe as a simplification.

A broad range of microorganisms can infect nematodes in a variety of ways. Different fungi, for example, have independently acquired the capacity to infect worms using diverse strategies (Lebrigand et al., 2016). Some species capture their prey with adhesive structure such as Arthobotrys oligosora or elegant mechanical traps like the constricting rings of 
Drechslerella doedycoides (Hsueh et al., 2017; Jansson, 1982; Maguire et al., 2011). Others infect with their non-motile spores that are either swallowed like Candida albicans or Harposorium spp., or adhere to the cuticle, like Haptocilium spp. or Drechmeria coniospora (Labed and Pujol, 2011). Most known C. elegans bacterial pathogens including Pseudomonas aeruginosa, Bacillus thuringiensis and Serratia marcescens infect the intestinal tract (Kurz et al., 2003; Mahajan-Miklos et al., 1999; Marroquin et al., 2000). Others attach to the cuticle, like Microbacterium nematophilum after oral ingestion (Parsons and Cipollo, 2014) or the uterus (Muir and Tan, 2008). Other worm pathogens are obligate and intracellular, like microsporidia and viruses. Most infect intestinal cells, but some have a broader tissue tropism (Luallen et al., 2016). Recently, an oomycete of the genus Myzocytiopsis was found to infect epidermal tissues in nematodes (Osman et al., 2018). Although there is now a broad catalogue of pathogens known to infect $C$. elegans, this is likely to be a fraction of those that exist in nature.

The microbiota of $C$. elegans has been defined as the community of bacteria found in the intestine and adhering to the animals' surface. The microbiota includes Proteobacteria, Actinobacteria, Bacteroidetes, and Firmicutes (Berg et al., 2016; Dirksen et al., 2016; Samuel et al., 2016) and seems to be substantially simpler than the microbiota of wild-caught drosophilid flies (Broderick and Lemaitre, 2012; Douglas, 2018). Interestingly, it appears to be selectively assembled from the host's environment and it is relatively similar in nematodes isolated from different origins, allowing a defined microbiota to be made available for future research (Dirksen et al., 2020). These studies have been reviewed recently (Kumar et al., 2020; Zhang et al., 2017) and will not be described in detail here.

The microbiota is suggested to be beneficial to the worm by several means like boosting the host immune response, providing health-promoting metabolites, competing with pathogens for space and resources, or by directly producing secondary metabolites that limit the growth of other microbes (Kumar et al., 2020). Interestingly, the host genotype can influence potentially beneficial mechanism, as in the case of Pseudomonas isolates that provide protection from Bacillus thuringiensis infection (Kissoyan et al., 2019), even changing a beneficial interaction into a detrimental one in the case of certain Enterobacter isolates (Berg et al., 2019). It is clear that the complexity and the variety of these interactions remain to be fully documented (Zimmermann et al., 2020).

\section{Surveillance-Activated Host Defence in C. elegans}

Eukaryotic organisms can activate a variety of immune responses to limit the harmful effects of pathogen exposure. Constant expression of these defences, however, represents a metabolic cost and additionally can be damaging to the host. For this reason, most immune pathways are kept in an inactive, but primed state. They can be activated by microbeassociated molecular patterns, or MAMPs, such as lipopolysaccharides, dsRNA, flagellin, and fungal polysaccharides (Tang et al., 2012). MAMPs are often detected by the Toll-Like Receptor (TLR) family of proteins or other families of pattern-recognition receptors (PRRs). Interestingly, C. elegans has only a single TLR protein, TOL-1/TLR, and it doesn't appear to have a role in direct MAMP recognition, although it is required to mediate the protection against Salmonella infection conferred by treatment with muramyl peptide (Rangan et al., 2016), and does play a role in pathogen aversion (Brandt and Ringstad, 2015; Pradel et al., 2007; Pujol et 
al., 2001). Apart from recognition of viral replication products by DRH-1/RIG-1 (Ashe et al., 2013), see below, examples of direct microbial detection that lead to immune pathway activation remain elusive in C. elegans (Kim and Ewbank, 2018).

Various molecules from the host, such as the protein HMGB1, formylated peptides, mitochondrial DNA, or uric acid, amongst many others, can also trigger innate immune activity (Tang et al., 2012). Matzinger and colleagues recognized that cells are agnostic with regard to the origin of the damage signals and will respond to them regardless of the preceding event, which led to the 'damage-associated molecular pattern' or DAMP hypothesis (Matzinger, 2002; Seong and Matzinger, 2004). On this basis, the field of innate immunity widened to include recognition of both non-self and self molecules.

Moreover, key cellular pathways and organelles are monitored, a process variously known as cellular surveillance-activated detoxification and defences (cSADDs) or surveillance immunity in C. elegans (Dunbar et al., 2012; McEwan et al., 2012; Melo and Ruvkun, 2012; PukkilaWorley, 2016) and broadly known as effector-triggered immunity in plants (Alhoraibi et al., 2019). Interestingly, the pathways activated by these triggers exhibit substantial overlap with known innate immune functions. For example, many of the best known innate immune pathways in $C$. elegans, such as the PMK-1/p38 MAPK kinase cascade and those activating SKN-1/Nrf and DAF-16/FOXO transcription factors, have been well-documented to respond to both biological and abiotic threats due to their effects on cellular function. These findings have blurred the boundaries of 'innate immune responses', overlapping with canonical stress responses, as will be reviewed below.

\section{Cell-autonomous response}

Conceptually, cell-autonomous responses are simple to understand. Cells detect the presence of pathogens, virulence determinants, or damage caused by infection, either within or outside of the cell. Host cells will then activate various responses in the attempt to clear the infection and mitigate the damage. The development of cell-autonomous defences to restore homeostasis was likely adopted at the very earliest stages of eukaryotic cellular existence, and as such are well-conserved across most eukaryotes.

The tissues most frequently involved in detecting cell autonomous damage are those exposed to the host's environment: the epidermis and the intestine. Frequently cited examples of cell autonomous innate immune responses include the upregulation of PMK-1/p38 MAPK dependant effectors in the intestine of $C$. elegans upon bacterial infection or in the epidermis upon fungal infection (Figure 1).

\section{Epidermal responses}

In nematodes, the skin is composed of the cuticle and its intimately linked underlying syncytial epidermis. The cuticle has two main functions: it forms an impermeable protective layer and is an exoskeleton. Disruption of the cuticle through fungal infection, physical injury or defects in specific cuticular collagens triggers an innate immune response in the epidermis mainly controlled by the STA-2/STAT transcription factor (Taffoni and Pujol, 2015). Loss of the same cuticular collagens also triggers an osmotic response in the epidermis, which is controlled by 
the ELT-3/GATA transcription factor and a detoxification response controlled by the SKN-1/Nrf transcription factor. This led to the suggestion that a common sensor lies in the cuticle, activated by damage, and translating complementary cellular responses in the epidermis (Dodd et al., 2018) (Figure 2). This hypothetical sensor remains to be identified, but it is possible that it will be involved in sensing mechanical stresses in the cuticle.

\section{Antimicrobial peptides induction in the epidermis}

The responses to several skin pathogens have been studied in $C$. elegans. Infection by the fungus $D$. coniospora triggers the rapid induction of several antimicrobial peptides genes in the epidermis, including those from the $n l p$ (for neuropeptide-like protein) and $c n c$ (caenacin) families (Couillault et al., 2004; Engelmann et al., 2011; Pujol et al., 2008b). These genes encode evolutionary-related antimicrobial peptides (AMPs) (Pujol et al., 2012); their overexpression can lead to an increased resistance to infection (Pujol et al., 2008b; Zugasti and Ewbank, 2009). Injury provokes a similar up-regulation of the nlp AMP genes, and triggers a cellular wound-healing and scarring mechanism (Pujol et al., 2008a; Xu and Chisholm, 2011), normally kept in check by nematode Death-associated protein kinase DAPK-1 (Tong et al., 2009). Recently, it was shown that cytoskeleton reorganization linking microtubule plus ends and actin during wound closure is required for immune activation suggesting that tissue repair and immune responses in the epidermis are tightly coordinated (Taffoni et al., 2020).

The highly conserved PMK-1/p38 MAPK signalling cascade is central to the activation of the induction of the nlp AMP genes (Figure 2) (Labed et al., 2012; Pujol et al., 2008a). It is activated upstream by a conserved protein kinase $C$ and signals to a STAT transcription factor-like protein, STA-2 (Dierking et al., 2011; Ziegler et al., 2009). Interestingly, a sodiumneurotransmitter symporter SNF-12, a member of the solute carrier family (SLC6) is key to the activation of STA-2. If it has been shown to be associated with the plasma membrane and to be recruited to the site of physical injury, its precise mode of action remains to be discovered (Taffoni et al., 2020). But this unorthodox mode of regulation for a STAT factor is one example of the molecular plasticity of innate immune signalling. SNF-12, STA-2, and the PMK-1 p38 MAPK pathway all lie downstream of the Ga protein GPA-12 (Dierking et al., 2011; Ziegler et al., 2009) and the G-protein coupled receptor (GPCR), DCAR-1. The tyrosine derivative 4hydroxyphenyllactic acid (HPLA) was identified as an endogenous ligand for DCAR-1. HPLA thus acts as a host-derived ligand, a bona fide DAMP on its cognate receptor DCAR-1 to trigger the epidermal innate immune response in C. elegans (Zugasti et al., 2014), highlighting the conserved role of GPCRs in host defence (Reboul and Ewbank, 2016).

Several chromatin-remodelling factors and the worm homolog of Akirin are also necessary for the induction of AMP gene expression after infection (Zugasti et al., 2016). In flies and vertebrates, Akirin couples NFKB signalling to SWI/SNF-dependent chromatin modification (Tartey et al., 2015). In C. elegans, Akirin acts rather with the NuRD chromatin-remodelling complex to modulate the action of a POU family transcription factor (Polanowska et al., 2018). Many questions remain open, such as whether pathogen recognition per se plays a role in the immune response to $D$. coniospora infection. This seems likely, given the fact that the transcriptional response to injury and infection do not fully overlap, and other skin pathogens, such as oomycetes provoke distinct defence reactions.

\section{Cuticle changes upon oomycetes infection}


Oomycetes are filamentous eukaryotes belonging to the phylum of heterokonts. Myzocytiopsis humicola, isolated from an environmental sample by M.A. Felix is a natural pathogen of $C$. elegans (Osman et al., 2018). Infection by M. humicola provokes a host response with limited similarity to that against other infections. One $c n c$ and $4 n / p$ AMP genes were among the less than $10 \%$ of genes that are induced commonly by $D$. coniospora and $M$. humicola infection. On the other hand, a family of genes encoding protein containing ALS2CR12 domain (pals) proteins are induced, in common with the response to infection by microsporidian parasites, as discussed below. In addition, this new pathosystem revealed a specific component of the immune response, a large family of chitinase-like (chil) genes strongly induced by $M$. humicola. Overexpression of chil-27 decreased the susceptibility of $C$. elegans to oomycete infection. CHIL-27 seems to act through changes in the stiffness of the cuticle of $C$. elegans, without affecting pathogen avoidance or pathogen attachment.

\section{Swelling response in response to a rectal infection}

The Gram-positive bacterium M. nematophilum adheres to the rectal cuticle, induces changes in intestinal gene expression and provokes a specific protective swelling of the tail (Hodgkin et al., 2000; O'Rourke et al., 2006). Direct genetic screens for mutants in which this response was suppressed allowed the identification of the "bacterially un-swollen" genes. A subset of these bus genes affects the adhesion of the bacteria to the cuticle. They correspond to genes involved in the production of the carbohydrate-rich surface coat proteins of the cuticle (Gravato-Nobre et al., 2005; Yook and Hodgkin, 2007). Although mutations in these genes reduce the interaction with $M$. nematophilum and therefore confer resistance to infection, they provoke the opposite phenotype, of increased adhesion and susceptibility during infection, with another cuticle-adhering bacteria of the genus Leucobacter (Hodgkin et al., 2013), or during infection with the fungus $D$. coniospora (Rouger et al., 2014). Thus, the composition of the cuticle surface coat seems to have a limited spectrum of potential diversification due to the balance of beneficial and detrimental interactions with microorganisms.

Upon $M$. nematophilum infection, the swelling response is driven by the activation of a canonical MPK-1/ERK MAPK pathway in the rectal epithelial cells by the Ras protein LET-60, identical to the cascade used for vulval development. In the rectum, it cooperates with a conserved EGL-30/Gaq - UNC-73/TrioRhoGEF - RHO-1/Rho signalling pathway, triggering changes in cell morphology via the RAF-MEK-ERK cassette (Figure 1) (McMullan et al., 2012; Nicholas and Hodgkin, 2004). The GPCR PCDR-1 acts upstream of EGL-30/G $\alpha$ for the clearance of the bacteria (Anderson et al., 2019a).

\section{Monitoring damage and infection of the intestine}

Since it naturally consumes bacteria, it is common for $C$. elegans to suffer intestinal infections in the wild. This makes it straightforward, and unusually simple, to develop $C$. elegans as a model for intestinal bacterial infections. Pioneering work by the Ausubel group was rapidly expanded to include many bacterial and fungal species of interest to humans (Aballay and Ausubel, 2002; Kim et al., 2002; Labrousse et al., 2000; Mallo et al., 2002; Pukkila-Worley et al., 2011). Detailed reviews have been written about many of the pathways involved and their conservation in mammals, including the importance of the MAPK pathways during infection 
(Kim and Ewbank, 2018), the roles played by autophagy during immunity (Kuo et al., 2018), and GPCR signalling in infection (Gupta and Singh, 2017; Reboul and Ewbank, 2016). Several important areas lack recent summaries or have seen considerable recent developments, and those will be the focus here.

\section{Monitoring the Machinery: Proteostasis as a Surveillance Target}

Perhaps the most heavily monitored homeostatic system in C. elegans is the interconnected proteostasis network, which spans the cytoplasm and most organelles. This network even extends to extracellular spaces, where proteostatic machinery has recently been identified and linked to the defence against infections (Gallotta et al., 2020). Proteostasis includes the regulation of translation, protein folding and misfolding, protein transport and trafficking, and destruction of misfolded proteins by the proteasome or autophagy. Disruptions to these processes will result in a variety of problems, ranging from the failure of normal metabolic pathways to the exposure of hydrophobic areas of misfolded proteins. Misfolded proteins can attract each other, causing aggregation and damage to other proteins and membranes (Nillegoda et al., 2018). Interestingly, Matzinger considered hydrophobicity to be one of the most likely candidates for general DAMPs (Seong and Matzinger, 2004). As such, it can serve as a sentinel cue for pathogen activity.

The translation of polypeptides is an important step in a wide variety of immune responses, as various effectors need to be produced rapidly to clear the infection and to mitigate the damage done by the pathogen. This has led to an arms race between host and pathogen, with a number of microbes developing proteins that can prevent protein translation, including exotoxin A from $P$. aeruginosa, Shiga toxin from Shigella flexneri, and Diphtheria toxin from Corynebacterium diphtheriae, amongst others. Hosts, in turn, have developed mechanisms to sense these inhibitory activities. C. elegans utilizes the bZIP transcription factors ZIP-2 and CEBP-2/CEBP $y$ to mediate the response to translational inhibition (Dunbar et al., 2012; McEwan et al., 2012; Reddy et al., 2016). More recent research has shown that the response also involves NIPI-3/Tribbles-mediated inhibition of CEBP-1/CEBPß in a pathway that may be parallel to ZIP-2 and CEBP-2 (McEwan et al., 2016).

\section{The Heat Shock Response: UPR in the Cytoplasm}

The most commonly studied proteostatic failure occurring upon infection is the accumulation of unfolded proteins in the ER, when the secretion system becomes overwhelmed following dramatic changes in gene expression. Other defence mechanisms, however, such as ROS production to destroy pathogens, can cause proteostatic stress (Ewald, 2018). Changes in chaperone expression are another frequent consequence of pathogen infection (Miles et al., 2019).

The detection of misfolded proteins in the cytoplasm by protein quality control components, activates a stress pathway that includes the DAF-16/FOXO3A and HSF-1/HSF1 transcription factors (Jones et al., 2020). This is part of the well-known heat shock response, conserved from yeast to vertebrates (Himanen and Sistonen, 2019). A number of proteostatic mechanisms are then induced, including upregulation of chaperones to favour folding, and of proteasomal subunits to degrade misfolded proteins, increased autophagosomal activity to soak up aggregates, and alterations to transcription and translation to slow the flow of de novo protein 
synthesis (Howard et al., 2016; Kumsta et al., 2017; Nillegoda et al., 2018; Vihervaara et al., 2018).

DAF-16/FOXO3A has a well-established role in host defence against intestinal bacterial pathogens. It acts in parallel with the p38 MAPK pathway to regulate defence gene expression (Miyata et al., 2008; Troemel et al., 2006). Recent work has suggested that as p38 MAPK activity declines with age, DAF-16 takes on an increasingly important role in host defence (McHugh et al., 2020). In addition, HSF-1/HSF1 plays a role in innate immunity in C. elegans, as $h s f-1$ mutants exhibit enhanced sensitivity to $P$. aeruginosa (Singh and Aballay, 2006) and HSF-1 facilitates the expression of genes that promote resistance to enteropathogenic $E$. coli (Anyanful et al., 2009). Interestingly, many unfolded protein responses, such as those controlled by HSF-1, alter the expression of a large number of non-coding RNAs, including representatives from most known ncRNA classes such as miRNAs, Piwi RNAs, lincRNAs, apparent pseudogenes, and even Helitron family transposons (Garrigues et al., 2019; Schreiner et al., 2019). The latter class contains over half of the HSF-1 binding sites in the $C$. elegans genome, and is enriched near genes up-regulated during heat shock. It was shown that different wild isolates of $C$. elegans contain strain-specific Helitron insertions, which may lead to diversification of HSF-1-dependent responses within natural populations (Garrigues et al., 2019). It will be interesting to see whether these translate into differences in the HSF-1dependent capacity to cope with periods of high temperature and/or immune response to resist better local pathogens.

\section{UPR in the ER}

One of the earliest demonstrations of a connection between the UPR ${ }^{E R}$ and host-pathogen interactions came from a genetic screen for mutants involved in the response to pore-forming toxins (PFTs). It led to the identification of a mutant that abrogates $\mathrm{N}$-glycosylation in the ER (Bischof et al., 2008), which is used as a checkpoint in the maturation of secretory proteins (Shenkman and Lederkremer, 2019). It is connected to the UPR ${ }^{E R}$ that involves ire-1/IRE1 $\alpha$, atf-6/ATF6, and pek-1/PERK. For its role in resistance to PFTs, the UPR ${ }^{E R}$ is required specifically in intestinal cells. IRE-1 acts through alerting the differential splicing of the mRNA for the transcription factor XBP-1 and thereby its activity (Bischof et al., 2008).

As mentioned above, activation of the PMK-1/p38 MAPK pathway is a common response to bacterial and fungal infection in C. elegans (Pujol et al., 2008a; Shivers et al., 2008; Troemel et al., 2006), leading to the secretion of innate immune effectors that transit through the ER, like lysozymes, lectins, and saposin-like proteins (Hoeckendorf et al., 2012; Kato et al., 2002; Mallo et al., 2002). It is not difficult to imagine that increased trafficking of these proteins may stress the folding capacity of the ER. Consistent with this model, the Kim lab showed that activation of PMK-1 by $P$. aeruginosa infection during larval development causes a lethal arrest in $C$. elegans $x b p-1$ mutants, which is fully rescued in a pmk-1 null mutant (Richardson et al., 2010). The deleterious effects of producing large quantities of secreted proteins in the absence of adequate quality control must outweigh the protection afforded by the p38 MAPK pathway (Ewbank and Pujol, 2010). PMK-1/p38 activity is thus controlled during development. NIPI-3, a member of the Tribbles pseudokinase family, has been shown to repress CEBP-1/CEBPß and to limit PMK-1/p38 MAPK activity during development (Kim et al., 2016b). The caspase CED-3 can directly target PMK-1 for cleavage, providing another mechanism for control of PMK-1 activity (Weaver et al., 2020). 
The UPR ${ }^{E R}$ can be activated even in the absence of excessive protein production. Amongst its other targets, PMK-1/p38 promotes the expression of the miRNA mir-233, which inhibits translation of the sarcoplasmic calcium transporter SCA-1 (Dai et al., 2015). Loss of SCA-1 depletes ER Ca ${ }^{2+}$ stores (Martin and Richmond, 2018), compromising function of ER-resident chaperones and triggering the UPRER directly (Melo and Ruvkun, 2012). One report has shown that downregulation of sca-1 improves survival during tunicamycin-induced ER stress (Howard et al., 2016). But as in the case of PMK-1/p38, SCA-1 has an opposite effect in larvae, as sca1(RNAi) impedes their development when exposed to tunicamycin (Hou et al., 2014). C. elegans may be negotiating a delicate balance between competing proteostatic maintenance programs in different cellular compartments during development. While searching for other mutations that could alleviate the developmental arrest of $x b p-1$ (tm2482) mutants cultured on $P$. aeruginosa, Kim and colleagues identified mutations in four transcriptional regulators ( $f k h-9$, arid-1, hcf-1, and $\sin -3)$. Surprisingly, mutations in $f k h-9$ or arid-1 caused arrest during development on the proteasomal inhibitor bortezomib, suggesting that an upregulation of ERassociated degradation (ERAD) in these mutants overwhelms the limited capacity of the proteasomes for ER-derived materials, leading to the accumulation of unfolded protein aggregates in the cytoplasm (Tillman et al., 2018).

\section{Lipid Activation of the UPR ${ }^{E R}$}

An unexpected recent discovery is that the UPR ${ }^{\mathrm{ER}}$ can also be activated by perturbations of cellular lipid biosynthesis or lipid pools (Hou et al., 2014; Koh et al., 2018). This response has been named UPR ${ }^{\mathrm{LBS}}$ (for lipid bilayer stress), to differentiate it from the consequences of accumulated unfolded proteins (UPR ${ }^{P T}$ for proteotoxicity). The two heat-shock proteins HSP3 and HSP-4 show different expression levels after activation of UPR ${ }^{\mathrm{PT}}$ and UPR ${ }^{\mathrm{LBS}}$, with the latter being more specific for UPR ${ }^{\mathrm{PT}}$ (Koh et al., 2018). It is interesting to note that HSP-3 has a role in the regulation of $n / p-29$ after $D$. coniospora infection that is not shared with HSP-4 (Couillault et al., 2012), suggesting that the UPR ${ }^{\text {LBS }}$ might be activated during fungal infection in the epidermis.

The UPR ${ }^{\mathrm{LBS}}$ can be activated by increased membrane disorder during lipid imbalance, which facilitates oligomerization of IRE-1 monomers. It can also be activated by ATF-6, which seems to detect the presence of dihydrosphingosine or dihydroceramide through its transmembrane domain (Fun and Thibault, 2020). Until recently, dihydroceramides and dihydrosphingosines were considered relatively inert biological molecules and were thought to merely be a transient product of ceramide metabolism (Siddique et al., 2015). Nichols and colleagues have, however, determined that phosphorylated dihydroceramides can be produced by a number of bacterial species that colonize and infect humans, including Porphyromonas gingivalis, and can activate host defence pathways (Nichols et al., 2011). The genes that are differentially expressed during UPR ${ }^{\mathrm{LBS}}$ only partially overlap with the genes of the UPR ${ }^{\mathrm{PT}}$. They include genes encoding innate immune effectors, proteostatic and autophagy machinery, chaperones, and genes involved in lipid metabolism (Fun and Thibault, 2020; Hou et al., 2014; Koh et al., 2018; Lajoie et al., 2012; Thibault et al., 2012). Disruption of phosphatidylcholine biosynthesis by compromising pmt-2/PEMT or the S-adenosyl methionine synthetase sams-1/MAT1A activate innate immune responses (Ding et al., 2015; Koh et al., 2018). This response, however, may not be protective, as loss of function of sams-1 causes hypersensitivity, rather than resistance to $P$. aeruginosa (Ding et al., 2015). 
Interestingly, spliced XBP-1 promotes the biosynthesis of oleic acid, which has previously been shown to reduce UPR ${ }^{\text {LBS }}$ (Ben-Dror and Birk, 2019). This may represent a feedback mechanism to facilitate UPR ${ }^{\mathrm{LBS}}$ suppression, as overactivation of the UPR ${ }^{\mathrm{ER}}$ is associated with increased autophagic activity (Koh et al., 2018) and can be lethal (Cheesman et al., 2016). Oleate has been shown to promote longevity in C. elegans (Gillingham et al., 2011; Goudeau et al., 2011; Han et al., 2017; Taylor and Dillin, 2013). This effect does not occur if spliced XBP-1 is constitutively expressed, suggesting that lifespan extension requires the activation of XBP-1. In addition, Oleate is important for the induction of innate immune effectors during bacterial infection (Anderson et al., 2019b), suggesting that it might have multiple roles in healthy aging. Indeed, lipids metabolism impacts innate immunity in multiple fashions (e.g. (Lee et al., 2010)), as exemplified by the recent demonstration that cholesterol, acting through the nuclear hormone receptor NHR-8, transcriptionally regulates immune genes through a crosstalk with the p38/PMK-1 MAPK, DAF-2/DAF-16 insulin pathway and the Nrf/SKN-1 pathways (Otarigho and Aballay, 2020).

\section{Mitochondrial Surveillance}

Mitochondria play important roles in a wide variety of biological processes, including oxidative phosphorylation, regulation of calcium levels, iron homeostasis, ROS production, and apoptosis. Considering these key functions, and the fact that many of them are specifically targeted during infection (Kwon et al., 2018; Tiku et al., 2020), it is perhaps unsurprising that they are subject to a variety of surveillance regimes.

Most mitochondrial proteins are encoded in the nucleus and need to be imported with an appropriate stoichiometry into the mitochondria (Rolland et al., 2019). Translocation requires the presence of specific transporters and chaperones and the establishment of a mitochondrial membrane potential (Dudek et al., 2013). The two best-characterized systems for monitoring mitochondrial import involve the translocation of a key protein that is degraded by mitochondria-resident proteases. The first, the PINK-1/PINK1-PDR-1/Parkin axis, uses failed PINK-1 import to target mitochondria for macroautophagy, known as mitophagy. This mitochondrial turnover is protective; blocking mitophagy during $P$. aeruginosa infection significantly increases host mortality (Kirienko et al., 2015).

This pathway is also involved in xenophagy, which is a phenomenon first described in mammals and involves a complex series of recognition and ubiquitinylation events that mark intracellular pathogens for autophagosomal degradation (McEwan, 2017). Less evidence exists for these events in C. elegans. Although involvement of autophagic machinery in hostpathogen defence has been described (Kuo et al., 2018; Visvikis et al., 2014), genuine xenophagic clearance of bacteria has yet to be demonstrated. This may be due to the fact that intracellular infections are comparatively rare in C. elegans, see below (Balla and Troemel, 2013).

Another import monitoring pathway, the mitochondrial URP (UPR ${ }^{\mathrm{mt}}$ ), takes advantage of the dual nuclear and mitochondrial targeting sequences in the ATFS-1/ATF5 transcription factor. Like mitophagy, this pathway has been reviewed in detail elsewhere (Gkikas et al., 2018; Melber and Haynes, 2018; Shpilka and Haynes, 2018; Yoo and Jung, 2018). Briefly, under normal circumstances ATFS-1/ATF5, which is constitutively expressed, is imported into mitochondria and promptly degraded (Naresh and Haynes, 2019). But when import fails, ATFS- 
1 is retargeted to the nucleus. Once there, it promotes the transcription of a variety of targets that are involved in protein folding, proteolysis, ROS detoxification machinery, iron-sulphur complex biogenesis, mitochondrial fission, and glycolysis. A more surprising group that is activated by ATFS-1 are genes associated with innate immunity, including abf-1, lys-2, clec-4, and zip-2 (Pellegrino et al., 2014; Wang et al., 2018). Disrupting ATFS-1 signalling reduced survival after infection with $P$. aeruginosa, supporting a crucial role for the UPR ${ }^{\mathrm{mt}}$ in innate immunity.

Exposure to the bacterial siderophore pyoverdine results in substantial host mitochondrial damage and death (Kirienko et al., 2015; Kirienko et al., 2013). This activates surveillance pathways, including the ethanol and stress response element (ESRE) network (Kang et al., 2018; Tjahjono and Kirienko, 2017). The ESRE network is linked to a variety of stress responses (Kirienko and Fay, 2010), and appears to respond to reductive stress caused by damage to the oxidative phosphorylation system (Tjahjono et al., 2020). ESRE effector genes are regulated by several different bZip transcription factors, including CEBP-1, CEBP-2, ZIP-2, and ZIP-4 (Tjahjono and Kirienko, 2017). Another member of the family, ZIP-3 has been suggested to negatively regulates ATFS- 1 in the context of phenazine-producing $P$. aeruginosa infection (Deng et al., 2019).

Several reports have linked UPR ${ }^{\text {mt }}$ to lipid homeostasis, through ceramide biosynthesis (Liu et al., 2014) or a more complex system called the mitochondria-to-cytosolic stress response (MCSR) (Kim et al., 2016a). We expect that these surveillance pathways will be linked to innate immunity as well, since they involve cellular mechanisms that can be exploited by pathogens.

\section{Oxidative Stress in Innate Immunity}

Oxidative stress is widely linked to decreased organismal viability. Healthy aging, in turn, is strongly correlated with resistance to infection. The free radical theory of aging postulates that reactive oxygen species (ROS) that are produced during oxidative phosphorylation cause damage to a wide variety of biomacromolecules, including DNA, lipids, and proteins (Pomatto and Davies, 2018). This reduces the ability of the organism to fight infection or manage stress, causes mutations and dysfunctions, and increases the rate of ROS production. Others suggest, based on studies in C. elegans, that ROS mediate a stress response to age-dependent damage, reviewed in (Hekimi et al., 2011).

In many cases, ROS are more than the accidental by-product of normal metabolic activity. For example, they are produced as important signalling molecules to activate defence networks (Ewald et al., 2017; Hourihan et al., 2016), as a consequence of proteasomal disruption (LivnatLevanon et al., 2014; Martinez et al., 2015; Segref et al., 2014), and contribute to self-defence for metazoan hosts infected with fungal or bacterial pathogens (Miranda-Vizuete and Veal, 2017). The complexity of ROS in C. elegans is illustrated by the multifunctional protein BLI$3 /$ Duox1. This protein includes an NADPH oxidase that generates superoxide and a peroxidase domain that utilizes peroxide for oxidizing various targets, including tyrosine residues in collagen to properly crosslink the cuticle (Edens et al., 2001). Although mutation in BLI-3 is developmentally lethal, in the adult, it sensitizes $C$. elegans to several pathogens including the Gram-positive bacterium Enterococcus faecalis (Chavez et al., 2009; Jain et al., 2009). ROS generated in this way activate SKN-1/Nrf via the PMK-1/p38 MAPK pathway, and SKN-1 activity promotes resistance to $E$. faecalis (Hoeven et al., 2011). Later work showed an 
unexpected role in the epidermis for two heme peroxidases, SKPO-1, a C. elegans ortholog of human lactoperoxidase, and HPX-2, which is homologous to several human heme-containing peroxidases, to protect the host against intestinal E. faecalis infection (Liu et al., 2019; Tiller and Garsin, 2014).

Proline metabolism was shown to be critically required for the production of hydrogen peroxide (Tang and Pang, 2016). Preventing ROS formation increases susceptibility to infection and reduces SKN-1/Nrf activation. Interestingly, SKN-1 activation in this context is partially dependent upon BLI-3/Duox. This, however, may be a risky gambit. A recent report suggests that hydrogen peroxide, or bacteria that produce it, can cause widespread damage, and may trigger cell cycle checkpoint failures in intestinal cells, which often undergo endoduplication events (Kniazeva and Ruvkun, 2019). While ROS can be a useful tool for host defence, they are not always a tool that is precise or easily controlled.

\section{Surveillance of Intracellular ROS}

Given the potential consequences of ROS activity, it is not surprising that organisms have developed mechanisms to monitor the levels of intracellular ROS. One involves the sulfenylation of a conserved cysteine residue on IRE-1 (Hourihan et al., 2016). This modification allows IRE-1 to activate the PMK-1/p38 MAPK cascade, which in turn activates SKN-1/Nrf. The latter is a well-known master regulator of detoxification, oxidative stress, proteasomal subunit transcription and pathogen responses (Blackwell et al., 2015), but recent discoveries have given new insights into its versatility and function.

C. elegans produces three SKN-1/Nrf isoforms: SKN-1A, SKN-1B, and SKN-1C. All three share the same C-terminal region, but exhibit differences in $\mathrm{N}$-termini, splice sites, expression patterns, and, intriguingly, patterns of protein sequence editing. SKN-1A is expressed in all tissues and contains a unique $\mathrm{N}$-terminal transmembrane domain that targets it to the ER (Glover-Cutter et al., 2013; Radhakrishnan et al., 2014; Wang and Chan, 2006). Once there, it is $\mathrm{N}$-glycosylated and promptly retrotranslocated back into the cytoplasm by the ERAD system and degraded by the proteasome. If SKN-1A is not degraded by the proteasome, it becomes a substrate for a peptide: $N$-glycanase that removes the $N$-linked glycans and converts the native asparagine into aspartate (Lehrbach et al., 2019; Lehrbach and Ruvkun, 2019). This allows it to be cleaved by an aspartic protease to yield a processed fragment of SKN-1 that specifically upregulates proteasomal subunit transcription (Lehrbach and Ruvkun, 2016). This provides an effective method of increasing proteasomal activity.

SKN-1B is produced in a single pair of sensory neurons, and appears to be involved in food sensing (Bishop and Guarente, 2007), but SKN-1C is produced only in the intestine and is licensed for transcriptional activity by oxidative stress. The innate immune function of SKN-1 has been associated with ELT-2 (Olaitan and Aballay, 2018), a GATA-family transcription factor that is essential for the development of the endoderm of $C$. elegans (Block et al., 2015). In the adult, the function of ELT-2 shifts to become essential for pathogen responses (Block and Shapira, 2015; Block et al., 2015; Head et al., 2017). This function requires physical interaction with RPT-6, a subunit of the $19 \mathrm{~S}$ proteasome (Olaitan and Aballay, 2018). Interestingly, this non-canonical function is consistent with other reports of proteasomal recruitment to transcriptional start sites (Durairaj and Kaiser, 2014). 


\section{Pore-forming toxins: Detecting a hole}

Pore-forming toxins (PFTs) are the largest class of bacterial toxins and are found in most, if not all, bacterial pathogens. They are critical pathogenic determinants across most pathogen groups, including the medically relevant genera Bacillus, Staphylococcus, Streptococcus, Escherichia, Salmonella, Vibrio, and Mycobacteria (Los et al., 2013). PFTs are generally secreted as water-soluble monomers that bind to receptors and recognition factors on the surface of cells. This has the effect of substantially increasing their local concentration, which facilitates oligomerization and membrane insertion (Dal Peraro and van der Goot, 2016). The formation of a pore in this fashion can cause a variety of consequences, ranging from slight increases in specific solute permeability to the rapid and complete destruction of cells. Others, like the listeriolysin $\mathrm{O}$ protein of Listeria monocytogenes, are thought to mediate immune evasion and phagocytic escape (Schnupf and Portnoy, 2007). Hosts respond to these insults by activating signal transduction pathways, triggering autophagy, and activating inflammasomes in more complex eukaryotes (Huffman et al., 2004; Kloft et al., 2010).

The responses of $C$. elegans to the crystal (Cry) PFTs from $B$. thuringiensis are arguably the most thoroughly characterized host-PFT interactions in the literature. The Cry proteins are produced by $B$. thuringiensis during sporulation, and have been widely used as insect and nematode control mechanisms in agriculture (Jouzani et al., 2017). Transferring the genes encoding the toxins to $E$. coli, or exposing worms to the purified toxins, is sufficient to kill $C$. elegans in 4-5 days. The first pathways identified that contribute to resistance to the Cry toxins were the PMK-1/p38 and KGB-1/JNK MAPK cascades (Huffman et al., 2004). The UPR ${ }^{E R}$ is required for PFT defence, possibly due to the increase in phospholipid biosynthesis, required for the extensive membrane remodelling that accompanies pore formation (Bischof et al., 2008). Vesicular trafficking pathways governed by the small GTPases RAB-5/Rab5 and RAB11/Rab11 are indeed required to counteract PFT activity but seem to be involved in two competing mechanisms. RAB-5 mediates increased endocytosis, possibly to facilitate autophagy, which has been linked with PFT defence (Chen et al., 2017b), or lysosomal degradation of the pore-containing vesicles. RAB-11, in contrast, triggers exocytotic events that appear to enable shedding of large amounts of apical surface material into the intestinal lumen in C. elegans (Los et al., 2011). Importantly, observations from insects and mammals have shown extrusion of the apical portion of enterocytes after PFT exposure (Lee et al., 2016), suggesting that this may be a conserved mechanism to maintain cell integrity. Recently, the endotube, a complex structure of cytoskeletal elements that underlies the brush border microvilli in C. elegans and that is conserved in mammals, was shown to protect against PFTs, possibly by limiting pathogen access to epithelial cell junctions (Geisler et al., 2019). This is consistent with a report demonstrating that $B$. thuringiensis Cry proteins are necessary, but not sufficient, for the disruption of these junctions and that this step is required for bacterial propagation in C. elegans (Wan et al., 2019).

Interestingly, the hypoxia-inducible factor HIF-1/HIF1 $\alpha$ plays a protective role against PFTs (Bellier et al., 2009). This function appears conserved, as cholera toxin activates HIF1 $\alpha$ in leukocytes (Royaee et al., 2006), and S. aureus secretes soluble factors that cause HIF1 $\alpha$ production in airway epithelial cells (Moreilhon et al., 2005). The protective effect of HIF-1 has been linked to at least two downstream factors: the transcription factor NHR-57/NR3C1, whose known activity is to restrict RAS/MAPK-induced differentiation in vulval precursor cells (Maxeiner et al., 2019), and the activation of the UPR ${ }^{E R}$ (Bellier et al., 2009). A satisfactory 
explanation for the involvement of HIF-1 in PFT resistance has yet to be suggested, and is illustrative of the vast territory remaining to be explored in understanding PFT virulence mechanisms and host immune defences.

\section{Intracellular pathogen response}

\section{Microsporidia}

Microsporidia is an early branching group of the fungi. Most organisms are colonized by microsporidians. Nematocida parisii, the most studied microsporidian infecting $C$. elegans, was isolated from compost near Paris (Troemel, 2016) but is found worldwide together with Nematocida ausubeli in wild-caught nematodes strains. Except for Pancytospora epiphaga, which proliferates mainly in the epidermis of its host, all other species infect intestinal cells (Zhang et al., 2016). Once swallowed, microsporidia spores use a specialized infection apparatus, the polar tube, which fires to inject the parasite into the host intestinal cell. Interestingly, Nematocida displodere with its unusually long polar tubes is able to infect distant tissue like muscle, epidermis and neurons (Luallen et al., 2016).

The parasite replicates intracellularly as a meront (multinucleated cell), which in turn differentiates into new spores that can survive outside their host as dormant spores. N. parisii can occupy the entire intestine of $C$. elegans without lysing intestinal cells. Instead, spores are contained in a membrane-bound compartment, which fuses with the apical membrane of the intestinal cell, leading to a directional exit, release and spread (Balla et al., 2016). This phenomenon might be due to a partial loss of cytoskeletal polarity and a redistribution of actin, leading to the formation of gaps in the terminal web. The small GTPases involved in apical recycling $\mathrm{RAB}-5, \mathrm{RAB}-10$ and $\mathrm{RAB}-11$ are important for spore egress in the intestinal lumen. More specifically, RAB-11 colocalizes with spores and is required for the fusion of the spore-containing compartment with the apical membrane (Szumowski et al., 2014). Interestingly, natural genetic variation can change the outcome of an infection by N. parisii, as some natural variants of $C$. elegans can clear Microsporidia infection (Balla et al., 2015).

\section{Viruses}

Viruses are obligate intracellular parasites and several Nodaviridae have been isolated from Caenorhabditis worms. Interestingly, they often appear to be species-specific, the Orsay virus, for example, infecting $C$. elegans but not $C$. briggsae (Franz et al., 2014). These viruses have two RNA fragments: RNA1 encoding an RNA-dependent RNA polymerase and RNA2 encoding a capsid and a novel ORF, the $\delta$ ORF. They infect intestinal cells and are transmitted via the oral-fecal route. Infection does not significantly affect worm longevity but does reduce fecundity. The first host antiviral defence to be identified was the RNA interference pathway that recognises and degrades viral RNA (reviewed in (Felix and Wang, 2019)). The RIG-I-like receptor DRH-1 is suggested to act as a pattern recognition receptor through the recognition of viral replication intermediates (Ashe et al., 2013). DRH-1/RIG-I shares a helicase domain with Dicer, central to dsRNA binding, and essential to an antiviral defence mechanism conserved from invertebrates to mammals (Paro et al., 2015; Sinha et al., 2018). A set of three genes, sid-3, viro-2 and nck-1 was found to be required for an early, pre-replication step of the Orsay virus's life cycle (Jiang et al., 2017; Tanguy et al., 2017). Subsequently, their mammalian 
orthologues TNK2, WASL and NCK1, respectively, were shown to regulate the entry of multiple picornaviruses through endocytosis and actin remodelling (Jiang et al., 2019). Another screen identified DRL-1 as necessary for a pre-replication step of the Orsay virus. DRL-1 is a putative serine/threonine kinase, ortholog to MEKK3. It is necessary for a pre-replication step of the Orsay virus (Sandoval et al., 2019). If Stat transcription factors are well characterised in antiviral response in mammals, only one of the 2 STAT factors in C. elegans STA- 1 appears to be involved but acts as a repressor of the antiviral response (Tanguy et al., 2017).

Uridylation is another antiviral defence mechanism acting in parallel to the RNAi pathway. It involves CDE-1, a 3' terminal RNA uridyltransferase, orthologous to the mammalian TUT4 and TUT7 enzymes (Le Pen et al., 2018). The immune response to the Orsay virus involves other unknown pathways, as shown by a meta-analysis of genes differentially expressed upon infection (Mishra et al., 2019). An independent pathway has been shown to be involved in an antiviral response to genomically encoded dsRNAs. LTR retrotransposons and endogenous retroviruses are normally silenced by ADARs (adenosine deaminases acting on dsRNA) editing and the ERI-6/7 RNAi pathway. Interestingly, in ADAR- or ERI-6-defective mutants, the activation of retrotransposons is associated with a UPR response, reflecting a shared proteotoxicity response, activated by excessive protein synthesis (Fischer and Ruvkun, 2020).

\section{Common responses to microsporidia \& viruses}

Interestingly, infections by the Orsay virus and the microsporidian N. parisii induce a common set of genes, which is the signature of the intracellular pathogen response (IPR) (Felix and Wang, 2019). It protects animals from proteotoxic stresses independently of the pathways described above (Reddy et al., 2017). The IPR is regulated by a switch composed of PALS-22 and PALS-25, which controls the balance between growth and pathogen resistance. PALS-22 acts as a suppressor, while PALS-25 acts as an activator (Reddy et al., 2019). The IPR promotes protein homeostasis via the ubiquitin ligase CUL-6, which functions together with the TRIM protein RCS-1 and the Skp-related proteins SKR-3, SKR-4, and SKR-5 (Bakowski et al., 2014; Panek et al., 2020). Interestingly, upon viral infection only, DRH-1/RIG-I acts independently of known RNAi factors to induce the IPR (Sowa et al., 2020).

\section{Cell non-autonomous response}

In addition to the cell autonomous mechanisms described above, in many circumstances, communication between the nervous system and other tissues is crucial to trigger an appropriate immune response. This communication can activate or suppress immune pathways to maintain organismal homeostasis. The sensory nervous system also controls physical avoidance of the pathogens, therefore reducing exposure and risk of infection. Neuro-immune communication involves several neuronal circuits, neurotransmitters and neuropeptides, G-protein-coupled receptors (GPCRs) and their ligands, transforming growth factor- $\beta$ ligands, and insulin signalling. These pathways have been extensively reviewed (Gupta and Singh, 2017; Reboul and Ewbank, 2016; Singh and Aballay, 2020; Wani et al., 2020). Other non-neuronal tissue communication mechanisms involved in maintaining the whole organism homeostasis have started to be revealed (Figure 3).

\section{Neuro-immune communication and regulation of the immune response}


Multiple neurotransmitters, such as serotonin, dopamine and acetylcholine have been identified as playing a role in the immune response, as reviewed in (Singh and Aballay, 2020; Wani et al., 2020). Recently, Sellegounder et al. showed that the monoamine octopamine acts as an endogenous ligand for the GPCR OCTR-1 to regulate the immune response to $P$. aeruginosa infection (Sellegounder et al., 2018). Octopamine is expressed in two RIC interneurons to suppress the innate immune response in the presence of non-pathogenic bacteria. Upon infection, this immune-inhibitory pathway is down-regulated to allow an appropriate immune response.

Identified as a neurotransmitter involved in behavioural avoidance of $M$. nematophilum (McMullan et al., 2012), acetylcholine can regulate the communication between neurons and the intestinal epithelium to induce an innate immune response (Labed et al., 2018). Upon infection with $S$. aureus, acetylcholine is released by the nervous system and activates the muscarinic GPCR receptors GAR-2 and GAR-3 in the intestine. This activation induces the expression of Wnt ligand (cwn-2) and Wnt Frizzled receptor (mig-1) in the intestine, responsible for the induction of downstream host defence genes in a BAR-1 ( $\beta$-catenin)dependent manner.

As described above, hyper-activation of p38-dependent immune responses in the intestine during development is deleterious, and can be efficiently suppressed by mutation in the $\mathrm{p} 38$ pathway or the transcription factor CEBP-1/CEBP $\beta$. Tissue-specific rescue experiments with cebp-1 revealed a coordinated tissue communication that keeps the required level of p38 throughout development (Kim et al., 2016b). More recently, it was shown that chemosensory neurons control the intestinal PMK-1/p38 MAPK pathway during development. Foster and colleagues isolated a mutant in the gene olrn-1 exhibiting a constitutive activation of the intestinal immune response gene irg-4 (Foster et al., 2020). OLRN-1 was known to be involved in olfactory learning, through antagonising specific voltage gated calcium channels in the chemosensory neuron AWC and thereby the activity of the p38 MAPK cassette (Huang et al., 2007). It is also OLRN-1 crucial for maintaining low p38 MAPK activity in the intestine during development (Foster et al., 2020).

\section{A diversity of avoidance responses}

Sensory neurons can mediate direct pathogen sensing to shape an appropriate response to pathogen exposure. C. elegans avoids the presence of Serratia marcescens through the recognition of a variety of strain-specific surfactants, each associated with a different sensory pathway. Serrawettin W2 elicits avoidance behaviour via two AWB chemosensory neurons, probably through G protein-coupled chemoreceptors (Pradel et al., 2007; Pujol et al., 2001). C. elegans avoids the toxin-producing Streptomyces through GPCR-based sensing of dodecanoic acid, this time by the receptor SRB-6 expressed in other chemosensory neurons (ASH, ADL and ADF) (Tran et al., 2017). Other bacteria, such as Bacillus anthracis, repel $C$. elegans without being a threat, possibly since they are recognised as a not good enough food source (Shtonda and Avery, 2006; Turner et al., 2020).

In addition, $C$. elegans can recognize nitric oxide (NO) produced by bacteria and uses it to detect $P$. aeruginosa, via the ASJ chemosensory neurons. If it requires the thioredoxin TRX-1, the cGMP-gated sensory channel TAX-4/TAX-2 and the receptor guanylate cyclases DAF-11 and GCY-27, the identity of the putative GPCR sensor is yet unknown (Hao et al., 2018). The 
ASJ neurons are also responsible for the detection of two $P$. aeruginosa secondary metabolites, phenazine-1-carboxamide and pyochelin. These activate a GPCR pathway leading to the production of a TGF- $\beta$ ligand (DAF-7) which then modulates aerotaxis behaviour, thereby favouring avoidance of pathogenic $P$. aeruginosa, as described below.

Another circuit that controls the response to $P$. aeruginosa infection involves the GPCR OCTR1. In the ASI neurons, it promotes pathogen avoidance, while in ASH neurons it inhibits immune pathways including the PMK-1/p38 MAPK, and the XBP-1 branch of the UPR, through the neuropeptide NLP-20 (Cao et al., 2017). After infection, OCTR-1 regulates innate immunity by modulating protein synthesis and inhibiting the UPR at the protein level (Liu et al., 2016). Pathogen avoidance is suggested to be mediated by the selenoprotein SELT-1.1 and the Ctype lectin C54G4.4. Although expressed in neurons, their mechanism of action has not been elucidated so far (Pees et al., 2017; Romanelli-Cedrez et al., 2017).

Tyramine signalling controls the touch response in $C$. elegans and is required for worms to extract themselves successfully from the traps of predacious fungi (Maguire et al., 2011). Interestingly, it was recently shown to modulate chemosensory choices. Tyramine produced by the gut commensal Providencia can be converted to octopamine by the host tyramine $\beta$ hydroxylase enzyme. The octopamine receptor OCTR-1 is then activated in the ASH nociceptive neurons to modulate an aversive olfactory response important for feeding choices (O'Donnell et al., 2020).

\section{$\mathrm{O}_{2} / \mathrm{CO}_{2}$ sensing}

C. elegans is attracted to areas of low oxygen concentration and avoids carbon dioxide in an NPR-1-dependent manner (Bretscher et al., 2008). As a consequence, it tends to accumulate where there are actively growing bacteria (bordering), unless it encounters any of the repulsive signals outlined above, in which case it integrates the different stimuli to determine the appropriate behaviour, in a mechanism that depends on TOL-1/TLR expressing neurons (Brandt and Ringstad, 2015). In a genetic screen for suppression of this bordering phenotype, de Bono and colleagues identified mutants in genes coding orthologues of a cytokine, interleukin-17, IL17.1, and its receptor ILCR-1. Activation of the ILCR-1 receptor on the hub neuron RMG potentiates its sensory input and mediates a sustained avoidance to high concentrations of oxygen. This activation goes through the paracaspase MALT-1 that forms a complex with homologs of Act1, IRAK and Ik $\beta$. Mutants in all the components of the complex exhibit a higher expression of defence genes and are more resistant to $P$. aeruginosa infection. Thus, IL17 links aversive behaviour to noxious cues and the immune response (Chen et al., 2017a; Flynn et al., 2020). IL-17 is a well described mammalian pro-inflammatory cytokine, induced by infection, damage and stress. Interestingly, its receptor is also expressed in the brain and was recently shown to be important in fear aversion in the mouse underlying a conserved role in behaviour (Alves de Lima et al., 2020; Rua and Pujol, 2020).

\section{Role of tissues in pathogen sensing}

It was suggested that the intestine might directly sense the infection and relay a signal to the nervous system. Interestingly, avoidance of different bacterial pathogens was enhanced for animals with bloated intestinal lumens, suggesting that intestinal distention could be perceived as a damage signal (Singh and Aballay, 2019). While it remains a possibility that 
bacterial metabolites contribute to this behaviour, there is an exciting possibility that it involves a mechanical sensor, monitoring the tension on the intestine, analogous to the putative mechanical sensor at the interface of the cuticle and epidermis (see above). Upon bacterial bloating, the aversive behaviour requires DAF-7/TGF $\beta$, the GPCR NPR-1 and its neuropeptides ligands FLP-18 and FLP-21. Concomitantly, it activates immune pathways for a complete immune response (Kumar et al., 2019; Singh and Aballay, 2019).

\section{Non-neuronal tissue communication}

While neuronal insulin is known to regulate intestinal immune response (Kawli and Tan, 2008), two independent studies revealed an induction of an insulin-like peptide in non-neuronal tissue upon infection. The insulin-like peptide INS-11 is upregulated upon $P$. aeruginosa infection and negatively regulates not the avoidance itself, but an aversive learning behaviour to $P$. aeruginosa (Lee and Mylonakis, 2017). The expression of ins-11 in the intestine is regulated by the transcription factor HLH-30 and the PMK-1/p38 MAPK pathway. INS-11 prevents the overexpression of ins- 6 in the ASI sensory neurons and of serotonin signalling in ADF sensory neurons. These pathways regulate aversive learning upon infection (Chen et al., 2013). Interestingly, the same insulin peptide INS-11 is strongly induced in the epidermis upon D. coniospora infection (Lee et al., 2018). In this tissue, ins-11 expression is similarly regulated by the PMK-1/p38 MAPK pathway, but by a different transcription factor, STA-2/STAT. These parallel studies showed that infection of different tissues, epidermis or intestine, leads to the production of the same insulin peptide from the infected tissue. In Drosophila, induction of an insulin-like peptide is used during development to coordinate organ growth (Boulan et al., 2019). INS-11 might serve as a sentinel during infection, alerting the organism when tissue homeostasis is perturbed, thus promoting optimal coordinated responses under stress conditions. In addition, other peptides are secreted by the infected tissues and might serve as a communication network, like the antimicrobial peptide NLP-29 that impacts neuronal survival (E et al., 2018) and sleep (Sinner et al., 2020).

\section{Stress and proteostasis}

As mentioned previously, the innate immune response and the maintenance of protein homeostasis are interconnected at the cell level. The regulation of proteostasis at the organismal level includes inter-tissue communication, as recently reviewed (Miles et al., 2019). It includes the heat-shock response (Prahlad et al., 2008), the UPR ${ }^{E R}$ (Taylor and Dillin, 2013), the UPR ${ }^{\mathrm{mt}}$ (Zhang et al., 2018), and transcellular chaperone signalling (O'Brien et al., 2018; van Oosten-Hawle et al., 2013). Recently, another connection has been made between the UPR ${ }^{m t}$ and innate immunity. FSHR-1/GPCR, which had previously been implicated in innate immunity via an unknown mechanism (Miller et al., 2015; Powell et al., 2009), acts non-cell autonomously in neurons to trigger the sphingosine kinase SPHK-1/SphK, which generates the sphingosine-1-phosphate required to induce UPR ${ }^{\mathrm{mt}}$ (Kim and Sieburth, 2018, 2020). Sphingosine-1-phosphate-mediated signalling was recently shown to increase immunity to $P$. aeruginosa infection in a p38 MAPK dependent manner (Lee et al., 2020).

Additional stress signalling pathways that regulate the innate immune response in a non-cell autonomous manner include the heat shock response (HSR), mediated by HSF-1 (Singh and Aballay, 2006), the UPR ${ }^{\mathrm{ER}}$, controlled by OCTR-1 in the nervous system (Singh and Aballay, 
2012; Sun et al., 2011), and the UPR ${ }^{m t}$ (Zugasti et al., 2016). For example, in the context of an epidermal infection by $D$. coniospora, an activation of the intestinal UPR ${ }^{\mathrm{mt}}$ through abrogation by RNAi of a range of mitochondrial genes inhibits antimicrobial peptide expression in the epidermis. The effect is cell non-autonomous since provoking the UPR ${ }^{\mathrm{mt}}$ only in the gut by knocking down spg-7 by RNAi in a tissue-specific manner abrogated epidermal AMP gene expression (Zugasti et al., 2016). Although this situation is analogous to other experimental paradigms of cross-tissue stress signalling in C. elegans (reviewed in (Ewbank and Pujol, 2016; Taylor et al., 2014; van Oosten-Hawle and Morimoto, 2014)), the molecular basis of such communication remains to be understood.

\section{Conclusion}

The past two decades of studying host-pathogen interactions in C. elegans have led to myriad discoveries that have helped our understanding of how hosts detect and respond to infection. These have narrowed the gap between the traditionally separate fields of innate immunity and stress responses. In addition to the examples described above, recent discoveries include the establishment of connections between pathogen responses and nucleolar function (Tiku et al., 2018), DNA damage (Bianco and Schumacher, 2018), detection of DNA in the cytoplasm (Williams et al., 2019) and splicing (Kew et al., 2020). There is every reason to believe that important discoveries are waiting to be made regarding other responses and surveillance pathways that are currently associated only either with stress or immunity.

Studies with $C$. elegans have also highlighted the incredible amount of communication that takes place between different tissues during infection, particularly between the nervous system and the intestine. It is unlikely that we have yet a measure of the true extent of intertissue communication in $C$. elegans. The secretion of chaperones in the extracellular spaces (pseudocoelom) to prevent aggregation during pathogenic attack is one very recent example (Gallotta et al., 2020). It will be necessary to use additional natural pathogens, and examine all tissues, such as muscles, to comprehend fully the extent of this crosstalk. It is clear that this humble model can continue to teach us much about homeostatic surveillance; after 20 years of research, the community has just scratched the surface.

\section{Figures Legends}

Figure 1. Cell-autonomous responses to infection. Examples of two canonical immune responses to infection, in the epidermis following infection by the fungus $D$. coniospora (Pujol et al., 2008a), and in the intestine by the bacterium $P$. aeruginosa (Troemel et al., 2006). Defence gene induction is observed with the transcriptional reporters, nlp-29p::GFP (left, epidermis) and irg-5p::GFP (right, intestine), the worms are visualised with an constitutive epidermal red fluorescent reporter (left) and in bright field (right).

Figure 2. Cell-autonomous regulation of innate immunity in C. elegans. Depending on the site of infection and on the pathogen, innate immunity is regulated through diverse pathways and effectors, see text for details.

Figure 3. Cross-tissue regulation of innate immunity in C. elegans. Innate immunity is regulated cell non-autonomously through direct or indirect communication between tissues. 


\section{Acknowledgement}

We thank Jonathan Ewbank for his detailed and constructive comments. We apologize for not being able to include all important work in this review. Work in our respective laboratories is funded by the Cancer Prevention and Research Institute of Texas (RR150044), the National Institutes of Health (NIGMS R35GM129294) (N.K.) and the French National Research Agency (ANR-16-CE15-0001-01), by the "Investissements d'Avenir » French Government program (ANR-16-CONV-0001) and from Excellence Initiative of Aix-Marseille University - A*MIDEX and institutional grants from CNRS, Aix Marseille University, National institute of Health and Medical Research (Inserm) to the CIML (C.M., N.P.).

\section{References}

Aballay, A., and Ausubel, F.M. (2002). Caenorhabditis elegans as a host for the study of host-pathogen interactions. Curr Opin Microbiol 5, 97-101.

Alhoraibi, H., Bigeard, J., Rayapuram, N., Colcombet, J., and Hirt, H. (2019). Plant Immunity: The MTI-ETI Model and Beyond. Curr Issues Mol Biol 30, 39-58.

Alves de Lima, K., Rustenhoven, J., Da Mesquita, S., Wall, M., Salvador, A.F., Smirnov, I., Martelossi Cebinelli, G., Mamuladze, T., Baker, W., Papadopoulos, Z., et al. (2020). Meningeal gammadelta T cells regulate anxiety-like behavior via IL-17a signaling in neurons. Nat Immunol 21, 1421-1429.

Anderson, A., Chew, Y.L., Schafer, W., and McMullan, R. (2019a). Identification of a Conserved, Orphan G Protein-Coupled Receptor Required for Efficient Pathogen Clearance in Caenorhabditis elegans. Infect Immun 87.

Anderson, S.M., Cheesman, H.K., Peterson, N.D., Salisbury, J.E., Soukas, A.A., and Pukkila-Worley, R. (2019b). The fatty acid oleate is required for innate immune activation and pathogen defense in Caenorhabditis elegans. PLoS Pathog 15, e1007893.

Anyanful, A., Easley, K.A., Benian, G.M., and Kalman, D. (2009). Conditioning protects C. elegans from lethal effects of enteropathogenic $E$. coli by activating genes that regulate lifespan and innate immunity. Cell Host Microbe 5, 450-462.

Ashe, A., Belicard, T., Le Pen, J., Sarkies, P., Frezal, L., Lehrbach, N.J., Felix, M.A., and Miska, E.A. (2013). A deletion polymorphism in the Caenorhabditis elegans RIG-I homolog disables viral RNA dicing and antiviral immunity. Elife 2, e00994.

Bakowski, M.A., Desjardins, C.A., Smelkinson, M.G., Dunbar, T.A., Lopez-Moyado, I.F., Rifkin, S.A., Cuomo, C.A., and Troemel, E.R. (2014). Ubiquitin-mediated response to microsporidia and virus infection in C. elegans. PLoS Pathog 10, e1004200.

Balla, K.M., Andersen, E.C., Kruglyak, L., and Troemel, E.R. (2015). A Wild C. elegans Strain Has Enhanced Epithelial Immunity to a Natural Microsporidian Parasite. PLoS Pathog 11, e1004583.

Balla, K.M., Luallen, R.J., Bakowski, M.A., and Troemel, E.R. (2016). Cell-to-cell spread of microsporidia causes Caenorhabditis elegans organs to form syncytia. Nat Microbiol 1, 16144.

Balla, K.M., and Troemel, E.R. (2013). Caenorhabditis elegans as a model for intracellular pathogen infection. Cellular microbiology 15, 1313-1322.

Bellier, A., Chen, C.S., Kao, C.Y., Cinar, H.N., and Aroian, R.V. (2009). Hypoxia and the hypoxic response pathway protect against pore-forming toxins in C. elegans. PLoS Pathog 5, e1000689.

Ben-Dror, K., and Birk, R. (2019). Oleic acid ameliorates palmitic acid-induced ER stress and inflammation markers in naive and cerulein-treated exocrine pancreas cells. Biosci Rep 39.

Berg, M., Monnin, D., Cho, J., Nelson, L., Crits-Christoph, A., and Shapira, M. (2019). TGF $\beta / B M P$ immune signaling affects abundance and function of $C$. elegans gut commensals. Nat Commun 10, 604.

Berg, M., Stenuit, B., Ho, J., Wang, A., Parke, C., Knight, M., Alvarez-Cohen, L., and Shapira, M. (2016). Assembly of the Caenorhabditis elegans gut microbiota from diverse soil microbial environments. ISME J 10, 1998-2009. 
Bianco, J.N., and Schumacher, B. (2018). MPK-1/ERK pathway regulates DNA damage response during development through DAF-16/FOXO. Nucleic Acids Res 46, 6129-6139.

Bischof, L.J., Kao, C.Y., Los, F.C., Gonzalez, M.R., Shen, Z., Briggs, S.P., van der Goot, F.G., and Aroian, R.V. (2008). Activation of the unfolded protein response is required for defenses against bacterial pore-forming toxin in vivo. PLoS Pathog 4, e1000176.

Bishop, N.A., and Guarente, L. (2007). Two neurons mediate diet-restriction-induced longevity in $C$. elegans. Nature 447, 545-549.

Blackwell, T.K., Steinbaugh, M.J., Hourihan, J.M., Ewald, C.Y., and Isik, M. (2015). SKN-1/Nrf, stress responses, and aging in Caenorhabditis elegans. Free Radic Biol Med 88, 290-301.

Block, D.H., and Shapira, M. (2015). GATA transcription factors as tissue-specific master regulators for induced responses. Worm 4, e1118607.

Block, D.H.S., Twumasi-Boateng, K., Kang, H.S., Carlisle, J.A., Hanganu, A., Lai, T.Y.-J., and Shapira, M. (2015). The Developmental Intestinal Regulator ELT-2 Controls p38-Dependent Immune Responses in Adult $C$. elegans. PLoS Genet 11, e1005265.

Boulan, L., Andersen, D., Colombani, J., Boone, E., and Leopold, P. (2019). Inter-Organ Growth Coordination Is Mediated by the Xrp1-Dilp8 Axis in Drosophila. Dev Cell 49, 811-818 e814.

Brandt, J.P., and Ringstad, N. (2015). Toll-like Receptor Signaling Promotes Development and Function of Sensory Neurons Required for a C. elegans Pathogen-Avoidance Behavior. Curr Biol 25, 2228-2237.

Bretscher, A.J., Busch, K.E., and de Bono, M. (2008). A carbon dioxide avoidance behavior is integrated with responses to ambient oxygen and food in Caenorhabditis elegans. Proc Natl Acad Sci U S A 105, 80448049.

Broderick, N.A., and Lemaitre, B. (2012). Gut-associated microbes of Drosophila melanogaster. Gut Microbes 3, 307-321.

Cao, J., Packer, J.S., Ramani, V., Cusanovich, D.A., Huynh, C., Daza, R., Qiu, X., Lee, C., Furlan, S.N., Steemers, F.J., et al. (2017). Comprehensive single-cell transcriptional profiling of a multicellular organism. Science 357, 661-667.

Chavez, V., Mohri-Shiomi, A., and Garsin, D.A. (2009). Ce-Duox1/BLI-3 generates reactive oxygen species as a protective innate immune mechanism in Caenorhabditis elegans. Infect Immun 77, 4983-4989.

Cheesman, H.K., Feinbaum, R.L., Thekkiniath, J., Dowen, R.H., Conery, A.L., and Pukkila-Worley, R. (2016). Aberrant Activation of p38 MAP Kinase-Dependent Innate Immune Responses Is Toxic to Caenorhabditis elegans. G3 (Bethesda) 6, 541-549.

Chen, C., Itakura, E., Nelson, G.M., Sheng, M., Laurent, P., Fenk, L.A., Butcher, R.A., Hegde, R.S., and de Bono, M. (2017a). IL-17 is a neuromodulator of Caenorhabditis elegans sensory responses. Nature 542, 43-48.

Chen, H.-D., Kao, C.-Y., Liu, B.-Y., Huang, S.-W., Kuo, C.-J., Ruan, J.-W., Lin, Y.-H., Huang, C.-R., Chen, Y.-H., Wang, H.-D., et al. (2017b). HLH-30/TFEB-mediated autophagy functions in a cell-autonomous manner for epithelium intrinsic cellular defense against bacterial pore-forming toxin in C. elegans. Autophagy 13, 371-385.

Chen, Z., Hendricks, M., Cornils, A., Maier, W., Alcedo, J., and Zhang, Y. (2013). Two insulin-like peptides antagonistically regulate aversive olfactory learning in C. elegans. Neuron 77, 572-585.

Couillault, C., Fourquet, P., Pophillat, M., and Ewbank, J.J. (2012). A UPR-independent infection-specific role for a BiP/GRP78 protein in the control of antimicrobial peptide expression in C. elegans epidermis. Virulence 3, 299-308.

Couillault, C., Pujol, N., Reboul, J., Sabatier, L., Guichou, J.F., Kohara, Y., and Ewbank, J.J. (2004). TLRindependent control of innate immunity in Caenorhabditis elegans by the TIR domain adaptor protein TIR-1, an ortholog of human SARM. Nat Immunol 5, 488-494.

Dai, L.L., Gao, J.X., Zou, C.G., Ma, Y.C., and Zhang, K.Q. (2015). mir-233 modulates the unfolded protein response in C. elegans during Pseudomonas aeruginosa infection. PLoS Pathog 11, e1004606.

Dal Peraro, M., and van der Goot, F.G. (2016). Pore-forming toxins: ancient, but never really out of fashion. Nat Rev Microbiol 14, 77-92.

Deng, P., Uma Naresh, N., Du, Y., Lamech, L.T., Yu, J., Zhu, L.J., Pukkila-Worley, R., and Haynes, C.M. (2019). Mitochondrial UPR repression during infection requires the bZIP protein ZIP-3. Proc Natl Acad Sci U S A 116, 6146-6151.

Dierking, K., Polanowska, J., Omi, S., Engelmann, I., Gut, M., Lembo, F., Ewbank, J.J., and Pujol, N. (2011). Unusual regulation of a STAT protein by an SLC6 family transporter in C. elegans epidermal innate immunity. Cell Host Microbe 9, 425-435.

Ding, W., Smulan, L.J., Hou, N.S., Taubert, S., Watts, J.L., and Walker, A.K. (2015). s-Adenosylmethionine Levels Govern Innate Immunity through Distinct Methylation-Dependent Pathways. Cell Metab 22, 633-645. 
Dirksen, P., Assie, A., Zimmermann, J., Zhang, F., Tietje, A.M., Marsh, S.A., Felix, M.A., Shapira, M., Kaleta, C., Schulenburg, H., et al. (2020). CeMbio - The Caenorhabditis elegans Microbiome Resource. G3 (Bethesda) 10, 3025-3039.

Dirksen, P., Marsh, S.A., Braker, I., Heitland, N., Wagner, S., Nakad, R., Mader, S., Petersen, C., Kowallik, V., Rosenstiel, P., et al. (2016). The native microbiome of the nematode Caenorhabditis elegans: gateway to a new host-microbiome model. BMC Biol 14, 38.

Dodd, W., Tang, L., Lone, J.C., Wimberly, K., Wu, C.W., Consalvo, C., Wright, J.E., Pujol, N., and Choe, K.P. (2018). A Damage Sensor Associated with the Cuticle Coordinates Three Core Environmental Stress Responses in Caenorhabditis elegans. Genetics 208, 1467-1482.

Douglas, A.E. (2018). The Drosophila model for microbiome research. Lab Animal 47, 157-164.

Dudek, J., Rehling, P., and van der Laan, M. (2013). Mitochondrial protein import: common principles and physiological networks. Biochim Biophys Acta 1833, 274-285.

Dunbar, T.L., Yan, Z., Balla, K.M., Smelkinson, M.G., and Troemel, E.R. (2012). C. elegans detects pathogeninduced translational inhibition to activate immune signaling. Cell Host Microbe 11, 375-386.

Durairaj, G., and Kaiser, P. (2014). The $26 \mathrm{~S}$ proteasome and initiation of gene transcription. Biomolecules 4, 827-847.

E, L., Zhou, T., Koh, S., Chuang, M., Sharma, R., Pujol, N., Chisholm, A.D., Eroglu, C., Matsunami, H., and Yan, D. (2018). An Antimicrobial Peptide and Its Neuronal Receptor Regulate Dendrite Degeneration in Aging and Infection. Neuron 97, 125-138 e125.

Edens, W.A., Sharling, L., Cheng, G., Shapira, R., Kinkade, J.M., Lee, T., Edens, H.A., Tang, X., Sullards, C., Flaherty, D.B., et al. (2001). Tyrosine cross-linking of extracellular matrix is catalyzed by Duox, a multidomain oxidase/peroxidase with homology to the phagocyte oxidase subunit gp91phox. J Cell Biol 154, 879-891.

Engelmann, I., Griffon, A., Tichit, L., Montanana-Sanchis, F., Wang, G., Reinke, V., Waterston, R.H., Hillier, L.W., and Ewbank, J.J. (2011). A comprehensive analysis of gene expression changes provoked by bacterial and fungal infection in C. elegans. PLoS One 6, e19055.

Ewald, C.Y. (2018). Redox Signaling of NADPH Oxidases Regulates Oxidative Stress Responses, Immunity and Aging. Antioxidants (Basel) 7.

Ewald, C.Y., Hourihan, J.M., Bland, M.S., Obieglo, C., Katic, I., Moronetti Mazzeo, L.E., Alcedo, J., Blackwell, T.K., and Hynes, N.E. (2017). NADPH oxidase-mediated redox signaling promotes oxidative stress resistance and longevity through memo-1 in C. elegans. Elife 6.

Ewbank, J.J., and Pujol, N. (2010). Cellular homeostasis: coping with ER overload during an immune response. Curr Biol 20, R452-455.

Ewbank, J.J., and Pujol, N. (2016). Local and long-range activation of innate immunity by infection and damage in C. elegans. Curr Opin Immunol 38, 1-7.

Felix, M.A., and Wang, D. (2019). Natural Viruses of Caenorhabditis Nematodes. Annu Rev Genet 53, 313326.

Fischer, S.E.J., and Ruvkun, G. (2020). Caenorhabditis elegans ADAR editing and the ERI-6/7/MOV10 RNAi pathway silence endogenous viral elements and LTR retrotransposons. Proceedings of the National Academy of Sciences 117, 5987-5996.

Flynn, S.M., Chen, C., Artan, M., Barratt, S., Crisp, A., Nelson, G.M., Peak-Chew, S.-Y., Begum, F., Skehel, M., and de Bono, M. (2020). MALT-1 mediates IL-17 neural signaling to regulate $C$. elegans behavior, immunity and longevity. Nat Commun 11, 2099.

Foster, K.J., Cheesman, H.K., Liu, P., Peterson, N.D., Anderson, S.M., and Pukkila-Worley, R. (2020). Innate Immunity in the $C$. elegans Intestine Is Programmed by a Neuronal Regulator of AWC Olfactory Neuron Development. Cell reports 31, 107478.

Franz, C.J., Renshaw, H., Frezal, L., Jiang, Y., Felix, M.A., and Wang, D. (2014). Orsay, Santeuil and Le Blanc viruses primarily infect intestinal cells in Caenorhabditis nematodes. Virology 448, 255-264.

Fun, X.H., and Thibault, G. (2020). Lipid bilayer stress and proteotoxic stress-induced unfolded protein response deploy divergent transcriptional and non-transcriptional programmes. Biochim Biophys Acta Mol Cell Biol Lipids 1865, 158449.

Gallotta, I., Sandhu, A., Peters, M., Haslbeck, M., Jung, R., Agilkaya, S., Blersch, J.L., Rodelsperger, C., Roseler, W., Huang, C., et al. (2020). Extracellular proteostasis prevents aggregation during pathogenic attack. Nature.

Garrigues, J.M., Tsu, B.V., Daugherty, M.D., and Pasquinelli, A.E. (2019). Diversification of the heat shock response by Helitron transposable elements. Elife 8 . 
Geisler, F., Coch, R.A., Richardson, C., Goldberg, M., Denecke, B., Bossinger, O., and Leube, R.E. (2019). The intestinal intermediate filament network responds to and protects against microbial insults and toxins. Development 146.

Gillingham, L.G., Harris-Janz, S., and Jones, P.J.H. (2011). Dietary monounsaturated fatty acids are protective against metabolic syndrome and cardiovascular disease risk factors. Lipids 46, 209-228.

Gkikas, I., Palikaras, K., and Tavernarakis, N. (2018). The Role of Mitophagy in Innate Immunity. Front Immunol 9, 1283.

Glover-Cutter, K.M., Lin, S., and Blackwell, T.K. (2013). Integration of the unfolded protein and oxidative stress responses through SKN-1/Nrf. PLoS Genet 9, e1003701.

Goudeau, J., Bellemin, S., Toselli-Mollereau, E., Shamalnasab, M., Chen, Y., and Aguilaniu, H. (2011). Fatty acid desaturation links germ cell loss to longevity through NHR-80/HNF4 in C. elegans. PLoS Biol 9, e1000599.

Gravato-Nobre, M., Hodgkin, J., and Ligoxygakis, P. (2020). From pathogen to a commensal: modification of the Microbacterium nematophilum-C. elegans interaction during chronic infection by the absence of host insulin signalling. Biol Open.

Gravato-Nobre, M.J., Nicholas, H.R., Nijland, R., O'Rourke, D., Whittington, D.E., Yook, K.J., and Hodgkin, J. (2005). Multiple genes affect sensitivity of Caenorhabditis elegans to the bacterial pathogen Microbacterium nematophilum. Genetics 171, 1033-1045.

Gupta, A., and Singh, V. (2017). GPCR Signaling in C. elegans and Its Implications in Immune Response. Adv Immunol 136, 203-226.

Han, S., Schroeder, E.A., Silva-García, C.G., Hebestreit, K., Mair, W.B., and Brunet, A. (2017). Monounsaturated fatty acids link H3K4me3 modifiers to $C$. elegans lifespan. Nature 544, 185-190.

Hao, Y., Yang, W., Ren, J., Hall, Q., Zhang, Y., and Kaplan, J.M. (2018). Thioredoxin shapes the C. elegans sensory response to Pseudomonas produced nitric oxide. Elife 7.

Head, B.P., Olaitan, A.O., and Aballay, A. (2017). Role of GATA transcription factor ELT-2 and p38 MAPK PMK-1 in recovery from acute $P$. aeruginosa infection in C. elegans. Virulence $8,261-274$.

Hekimi, S., Lapointe, J., and Wen, Y. (2011). Taking a "good" look at free radicals in the aging process. Trends Cell Biol 21, 569-576.

Himanen, S.V., and Sistonen, L. (2019). New insights into transcriptional reprogramming during cellular stress. J Cell Sci 132.

Hodgkin, J., Felix, M.A., Clark, L.C., Stroud, D., and Gravato-Nobre, M.J. (2013). Two Leucobacter strains exert complementary virulence on Caenorhabditis including death by worm-star formation. Current biology : CB 23, 2157-2161.

Hodgkin, J., Kuwabara, P.E., and Corneliussen, B. (2000). A novel bacterial pathogen, Microbacterium nematophilum, induces morphological change in the nematode C. elegans. Curr Biol 10, 1615-1618.

Hoeckendorf, A., Stanisak, M., and Leippe, M. (2012). The saposin-like protein SPP-12 is an antimicrobial polypeptide in the pharyngeal neurons of Caenorhabditis elegans and participates in defence against a natural bacterial pathogen. Biochem J 445, 205-212.

Hoeven, R., McCallum, K.C., Cruz, M.R., and Garsin, D.A. (2011). Ce-Duox1/BLI-3 generated reactive oxygen species trigger protective SKN-1 activity via p38 MAPK signaling during infection in C. elegans. PLoS Pathog 7, e1002453.

Hou, N.S., Gutschmidt, A., Choi, D.Y., Pather, K., Shi, X., Watts, J.L., Hoppe, T., and Taubert, S. (2014). Activation of the endoplasmic reticulum unfolded protein response by lipid disequilibrium without disturbed proteostasis in vivo. Proc Natl Acad Sci U S A 111, E2271-2280.

Hourihan, J.M., Moronetti Mazzeo, L.E., Fernández-Cárdenas, L.P., and Blackwell, T.K. (2016). Cysteine Sulfenylation Directs IRE-1 to Activate the SKN-1/Nrf2 Antioxidant Response. Mol Cell 63, 553-566.

Howard, A.C., Rollins, J., Snow, S., Castor, S., and Rogers, A.N. (2016). Reducing translation through eIF4G/IFG-1 improves survival under ER stress that depends on heat shock factor HSF-1 in Caenorhabditis elegans. Aging Cell 15, 1027-1038.

Hsueh, Y.P., Gronquist, M.R., Schwarz, E.M., Nath, R.D., Lee, C.H., Gharib, S., Schroeder, F.C., and Sternberg, P.W. (2017). Nematophagous fungus Arthrobotrys oligospora mimics olfactory cues of sex and food to lure its nematode prey. Elife 6 .

Huang, S.L.B., Bauer Huang, S.L., Saheki, Y., VanHoven, M.K., Torayama, I., Ishihara, T., Katsura, I., van der Linden, A., Sengupta, P., and Bargmann, C.I. (2007). Left-right olfactory asymmetry results from antagonistic functions of voltage-activated calcium channels and the Raw repeat protein OLRN-1 in C. elegans. Neural Development 2, 24. 
Huffman, D.L., Abrami, L., Sasik, R., Corbeil, J., van der Goot, F.G., and Aroian, R.V. (2004). Mitogenactivated protein kinase pathways defend against bacterial pore-forming toxins. Proc Natl Acad Sci U S A 101, 10995-11000

Jain, C., Yun, M., Politz, S.M., and Rao, R.P. (2009). A pathogenesis assay using Saccharomyces cerevisiae and Caenorhabditis elegans reveals novel roles for yeast AP-1, Yap1, and host dual oxidase BLI-3 in fungal pathogenesis. Eukaryot Cell 8, 1218-1227.

Jansson, H.B. (1982). Attraction of nematodes to endo-parasitic nematophagous fungi. Trans Brit Mycol Soc 79, 25-29.

Jiang, H., Chen, K., Sandoval, L.E., Leung, C., and Wang, D. (2017). An Evolutionarily Conserved Pathway Essential for Orsay Virus Infection of Caenorhabditis elegans. MBio 8.

Jiang, H., Leung, C., Tahan, S., and Wang, D. (2019). Entry by multiple picornaviruses is dependent on a pathway that includes TNK2, WASL, and NCK1. Elife 8.

Jones, L.M., Chen, Y., and van Oosten-Hawle, P. (2020). Redefining proteostasis transcription factors in organismal stress responses, development, metabolism, and health. Biol Chem.

Jouzani, G.S., Valijanian, E., and Sharafi, R. (2017). Bacillus thuringiensis: a successful insecticide with new environmental features and tidings. Appl Microbiol Biotechnol 101, 2691-2711.

Kang, D., Kirienko, D.R., Webster, P., Fisher, A.L., and Kirienko, N.V. (2018). Pyoverdine, a siderophore from Pseudomonas aeruginosa, translocates into $C$. elegans, removes iron, and activates a distinct host response. Virulence 9, 804-817.

Kato, Y., Aizawa, T., Hoshino, H., Kawano, K., Nitta, K., and Zhang, H. (2002). abf-1 and abf-2, ASABF-type antimicrobial peptide genes in Caenorhabditis elegans. Biochem J 361, 221-230.

Kawli, T., and Tan, M.W. (2008). Neuroendocrine signals modulate the innate immunity of Caenorhabditis elegans through insulin signaling. Nat Immunol 9, 1415-1424.

Kew, C., Huang, W., Fischer, J., Ganesan, R., Robinson, N., and Antebi, A. (2020). Evolutionarily conserved regulation of immunity by the splicing factor RNP-6/PUF60. Elife 9.

Khan, F., Jain, S., and Oloketuyi, S.F. (2018). Bacteria and bacterial products: Foe and friends to Caenorhabditis elegans. Microbiol Res 215, 102-113.

Kim, D.H., and Ewbank, J.J. (2018). Signaling in the innate immune response. In WormBook (The C. elegans Research Community ed.), pp. 1-35.

Kim, D.H., Feinbaum, R., Alloing, G., Emerson, F.E., Garsin, D.A., Inoue, H., Tanaka-Hino, M., Hisamoto, N., Matsumoto, K., Tan, M.W., et al. (2002). A conserved p38 MAP kinase pathway in Caenorhabditis elegans innate immunity. Science 297, 623-626.

Kim, H.-E., Grant, A.R., Simic, M.S., Kohnz, R.A., Nomura, D.K., Durieux, J., Riera, C.E., Sanchez, M., Kapernick, E., Wolff, S., et al. (2016a). Lipid Biosynthesis Coordinates a Mitochondrial-to-Cytosolic Stress Response. Cell 166, 1539-1552.e1516.

Kim, K.W., Thakur, N., Piggott, C.A., Omi, S., Polanowska, J., Jin, Y., and Pujol, N. (2016b). Coordinated inhibition of C/EBP by Tribbles in multiple tissues is essential for Caenorhabditis elegans development. BMC Biol 14, 104

Kim, S., and Sieburth, D. (2018). Sphingosine Kinase Activates the Mitochondrial Unfolded Protein Response and Is Targeted to Mitochondria by Stress. Cell Rep 24, 2932-2945.e2934.

Kim, S., and Sieburth, D. (2020). FSHR-1/GPCR Regulates the Mitochondrial Unfolded Protein Response in. Genetics 214, 409-418.

Kirienko, N.V., Ausubel, F.M., and Ruvkun, G. (2015). Mitophagy confers resistance to siderophoremediated killing by Pseudomonas aeruginosa. P Natl Acad Sci USA 112, 1821-1826.

Kirienko, N.V., and Fay, D.S. (2010). SLR-2 and JMJC-1 regulate an evolutionarily conserved stressresponse network. EMBO J 29, 727-739.

Kirienko, N.V., Kirienko, D.R., Larkins-Ford, J., Wählby, C., Ruvkun, G., and Ausubel, F.M. (2013). Pseudomonas aeruginosa disrupts Caenorhabditis elegans iron homeostasis, causing a hypoxic response and death. Cell Host Microbe 13, 406-416.

Kissoyan, K.A.B., Drechsler, M., Stange, E.L., Zimmermann, J., Kaleta, C., Bode, H.B., and Dierking, K. (2019). Natural C. elegans Microbiota Protects against Infection via Production of a Cyclic Lipopeptide of the Viscosin Group. Curr Biol 29, 1030-1037 e1035.

Kloft, N., Neukirch, C., Bobkiewicz, W., Veerachato, G., Busch, T., von Hoven, G., Boller, K., and Husmann, M. (2010). Pro-autophagic signal induction by bacterial pore-forming toxins. Med Microbiol Immunol 199, 299309.

Kniazeva, M., and Ruvkun, G. (2019). Rhizobium induces DNA damage in Caenorhabditis elegans intestinal cells. Proc Natl Acad Sci U S A 116, 3784-3792. 
Koh, J.H., Wang, L., Beaudoin-Chabot, C., and Thibault, G. (2018). Lipid bilayer stress-activated IRE-1 modulates autophagy during endoplasmic reticulum stress. J Cell Sci 131.

Kumar, A., Baruah, A., Tomioka, M., lino, Y., Kalita, M.C., and Khan, M. (2020). Caenorhabditis elegans: a model to understand host-microbe interactions. Cell Mol Life Sci 77, 1229-1249.

Kumar, S., Egan, B.M., Kocsisova, Z., Schneider, D.L., Murphy, J.T., Diwan, A., and Kornfeld, K. (2019). Lifespan Extension in C. elegans Caused by Bacterial Colonization of the Intestine and Subsequent Activation of an Innate Immune Response. Dev Cell 49, 100-117 e106.

Kumsta, C., Chang, J.T., Schmalz, J., and Hansen, M. (2017). Hormetic heat stress and HSF-1 induce autophagy to improve survival and proteostasis in C. elegans. Nat Commun 8, 14337.

Kuo, C.J., Hansen, M., and Troemel, E. (2018). Autophagy and innate immunity: Insights from invertebrate model organisms. Autophagy 14, 233-242.

Kurz, C.L., Chauvet, S., Andres, E., Aurouze, M., Vallet, I., Michel, G.P., Uh, M., Celli, J., Filloux, A., De Bentzmann, S., et al. (2003). Virulence factors of the human opportunistic pathogen Serratia marcescens identified by in vivo screening. Embo J 22, 1451-1460.

Kwon, S., Kim, E.J.E., and Lee, S.-J.V. (2018). Mitochondria-mediated defense mechanisms against pathogens in Caenorhabditis elegans. BMB Rep 51, 274-279.

Labed, S., and Pujol, N. (2011). Caenorhabditis elegans Antifungal Defense Mechanisms. The Journal of Invasive Fungal Infection 5, 110-117.

Labed, S.A., Omi, S., Gut, M., Ewbank, J.J., and Pujol, N. (2012). The pseudokinase NIPI-4 is a novel regulator of antimicrobial peptide gene expression. PLoS One 7, e33887.

Labed, S.A., Wani, K.A., Jagadeesan, S., Hakkim, A., Najibi, M., and Irazoqui, J.E. (2018). Intestinal Epithelial Wnt Signaling Mediates Acetylcholine-Triggered Host Defense against Infection. Immunity 48, 963-978 e963.

Labrousse, A., Chauvet, S., Couillault, C., Kurz, C.L., and Ewbank, J.J. (2000). Caenorhabditis elegans is a model host for Salmonella typhimurium. Curr Biol 10, 1543-1545.

Lajoie, P., Moir, R.D., Willis, I.M., and Snapp, E.L. (2012). Kar2p availability defines distinct forms of endoplasmic reticulum stress in living cells. Mol Biol Cell 23, 955-964.

Le Pen, J., Jiang, H., Di Domenico, T., Kneuss, E., Kosalka, J., Leung, C., Morgan, M., Much, C., Rudolph, K.L.M., Enright, A.J., et al. (2018). Terminal uridylyltransferases target RNA viruses as part of the innate immune system. Nat Struct Mol Biol 25, 778-786.

Lebrigand, K., He, L.D., Thakur, N., Arguel, M.J., Polanowska, J., Henrissat, B., Record, E., Magdelenat, G., Barbe, V., Raffaele, S., et al. (2016). Comparative Genomic Analysis of Drechmeria coniospora Reveals Core and Specific Genetic Requirements for Fungal Endoparasitism of Nematodes. PLoS Genet 12, e1006017.

Lee, K.-Z., Lestradet, M., Socha, C., Schirmeier, S., Schmitz, A., Spenlé, C., Lefebvre, O., Keime, C., Yamba, W.M., Bou Aoun, R., et al. (2016). Enterocyte Purge and Rapid Recovery Is a Resilience Reaction of the Gut Epithelium to Pore-Forming Toxin Attack. Cell Host Microbe 20, 716-730.

Lee, K., Escobar, I., Jang, Y., Kim, W., Ausubel, F.M., and Mylonakis, E. (2020). In the Model Host Caenorhabditis elegans, Sphingosine-1-Phosphate-Mediated Signaling Increases Immunity toward Human Opportunistic Bacteria. Int J Mol Sci 21.

Lee, K., and Mylonakis, E. (2017). An Intestine-Derived Neuropeptide Controls Avoidance Behavior in Caenorhabditis elegans. Cell reports 20, 2501-2512.

Lee, K.Z., Kniazeva, M., Han, M., Pujol, N., and Ewbank, J.J. (2010). The fatty acid synthase fasn-1 acts upstream of WNK and Ste20/GCK-VI kinases to modulate antimicrobial peptide expression in C. elegans epidermis. Virulence 1, 113 - 122.

Lee, S.H., Omi, S., Thakur, N., Taffoni, C., Belougne, J., Engelmann, I., Ewbank, J.J., and Pujol, N. (2018). Modulatory upregulation of an insulin peptide gene by different pathogens in C. elegans. Virulence 9, 648-658. Lehrbach, N.J., Breen, P.C., and Ruvkun, G. (2019). Protein Sequence Editing of SKN-1A/Nrf1 by Peptide:NGlycanase Controls Proteasome Gene Expression. Cell 177, 737-750.e715.

Lehrbach, N.J., and Ruvkun, G. (2016). Proteasome dysfunction triggers activation of SKN-1A/Nrf1 by the aspartic protease DDI-1. Elife 5.

Lehrbach, N.J., and Ruvkun, G. (2019). Endoplasmic reticulum-associated SKN-1A/Nrf1 mediates a cytoplasmic unfolded protein response and promotes longevity. Elife 8.

Liu, Y., Kaval, K.G., van Hoof, A., and Garsin, D.A. (2019). Heme peroxidase HPX-2 protects Caenorhabditis elegans from pathogens. PLoS Genet 15, e1007944.

Liu, Y., Samuel, B.S., Breen, P.C., and Ruvkun, G. (2014). Caenorhabditis elegans pathways that surveil and defend mitochondria. Nature 508, 406-410.

Liu, Y., Sellegounder, D., and Sun, J. (2016). Neuronal GPCR OCTR-1 regulates innate immunity by controlling protein synthesis in Caenorhabditis elegans. Sci Rep 6, 36832. 
Livnat-Levanon, N., Kevei, E., Kleifeld, O., Krutauz, D., Segref, A., Rinaldi, T., Erpapazoglou, Z., Cohen, M., Reis, N., Hoppe, T., et al. (2014). Reversible $26 \mathrm{~S}$ proteasome disassembly upon mitochondrial stress. Cell reports $7,1371-1380$.

Los, F.C., Kao, C.Y., Smitham, J., McDonald, K.L., Ha, C., Peixoto, C.A., and Aroian, R.V. (2011). RAB-5- and RAB-11-Dependent Vesicle-Trafficking Pathways Are Required for Plasma Membrane Repair after Attack by Bacterial Pore-Forming Toxin. Cell Host Microbe 9, 147-157.

Los, F.C.O., Randis, T.M., Aroian, R.V., and Ratner, A.J. (2013). Role of pore-forming toxins in bacterial infectious diseases. Microbiol Mol Biol Rev 77, 173-207.

Luallen, R.J., Reinke, A.W., Tong, L., Botts, M.R., Felix, M.A., and Troemel, E.R. (2016). Discovery of a Natural Microsporidian Pathogen with a Broad Tissue Tropism in Caenorhabditis elegans. PLoS Pathog 12, e1005724.

Maguire, S.M., Clark, C.M., Nunnari, J., Pirri, J.K., and Alkema, M.J. (2011). The C. elegans Touch Response Facilitates Escape from Predacious Fungi. Curr Biol 21, 1326-1330.

Mahajan-Miklos, S., Tan, M.W., Rahme, L.G., and Ausubel, F.M. (1999). Molecular mechanisms of bacterial virulence elucidated using a Pseudomonas aeruginosa-Caenorhabditis elegans pathogenesis model. Cell 96, 4756.

Mallo, G.V., Kurz, C.L., Couillault, C., Pujol, N., Granjeaud, S., Kohara, Y., and Ewbank, J.J. (2002). Inducible antibacterial defense system in C. elegans. Curr Biol 12, 1209-1214.

Marroquin, L.D., Elyassnia, D., Griffitts, J.S., Feitelson, J.S., and Aroian, R.V. (2000). Bacillus thuringiensis $(B t)$ toxin susceptibility and isolation of resistance mutants in the nematode Caenorhabditis elegans. Genetics 155, 1693-1699.

Martin, A.A., and Richmond, J.E. (2018). The sarco(endo)plasmic reticulum calcium ATPase SCA-1 regulates the Caenorhabditis elegans nicotinic acetylcholine receptor ACR-16. Cell Calcium 72, 104-115.

Martinez, B.A., Kim, H., Ray, A., Caldwell, G.A., and Caldwell, K.A. (2015). A bacterial metabolite induces glutathione-tractable proteostatic damage, proteasomal disturbances, and PINK1-dependent autophagy in $C$. elegans. Cell Death Dis 6, e1908.

Matzinger, P. (2002). The danger model: a renewed sense of self. Science 296, 301-305.

Maxeiner, S., Grolleman, J., Schmid, T., Kammenga, J., and Hajnal, A. (2019). The hypoxia-response pathway modulates RAS/MAPK-mediated cell fate decisions in. Life Sci Alliance 2.

McEwan, D.G. (2017). Host-pathogen interactions and subversion of autophagy. Essays Biochem 61, 687697.

McEwan, D.L., Feinbaum, R.L., Stroustrup, N., Haas, W., Conery, A.L., Anselmo, A., Sadreyev, R., and Ausubel, F.M. (2016). Tribbles ortholog NIPI-3 and bZIP transcription factor CEBP-1 regulate a Caenorhabditis elegans intestinal immune surveillance pathway. BMC Biol 14, 105.

McEwan, D.L., Kirienko, N.V., and Ausubel, F.M. (2012). Host translational inhibition by Pseudomonas aeruginosa Exotoxin A Triggers an immune response in Caenorhabditis elegans. Cell Host Microbe 11, 364-374.

McHugh, D.R., Koumis, E., Jacob, P., Goldfarb, J., Schlaubitz-Garcia, M., Bennani, S., Regan, P., Patel, P., and Youngman, M.J. (2020). DAF-16 and SMK-1 Contribute to Innate Immunity During Adulthood in Caenorhabditis elegans. G3 (Bethesda) 10, 1521-1539.

McMullan, R., Anderson, A., and Nurrish, S. (2012). Behavioral and Immune Responses to Infection Require Galphaq- RhoA Signaling in C. elegans. PLoS Pathog 8, e1002530.

Melber, A., and Haynes, C.M. (2018). UPR(mt) regulation and output: a stress response mediated by mitochondrial-nuclear communication. Cell Res 28, 281-295.

Melo, J.A., and Ruvkun, G. (2012). Inactivation of conserved C. elegans genes engages pathogen- and xenobiotic-associated defenses. Cell 149, 452-466.

Miles, J., Scherz-Shouval, R., and van Oosten-Hawle, P. (2019). Expanding the Organismal Proteostasis Network: Linking Systemic Stress Signaling with the Innate Immune Response. Trends Biochem Sci.

Miller, E.V., Grandi, L.N., Giannini, J.A., Robinson, J.D., and Powell, J.R. (2015). The Conserved G-Protein Coupled Receptor FSHR-1 Regulates Protective Host Responses to Infection and Oxidative Stress. PLoS One 10, e0137403.

Miranda-Vizuete, A., and Veal, E.A. (2017). Caenorhabditis elegans as a model for understanding ROS function in physiology and disease. Redox Biol 11, 708-714.

Mishra, P., Ngo, J., Ashkani, J., and Pio, F. (2019). Meta-analysis suggests evidence of novel stress-related pathway components in Orsay virus - Caenorhabditis elegans viral model. Sci Rep 9, 4399.

Miyata, S., Begun, J., Troemel, E.R., and Ausubel, F.M. (2008). DAF-16-dependent suppression of immunity during reproduction in Caenorhabditis elegans. Genetics 178, 903-918. 
Moreilhon, C., Gras, D., Hologne, C., Bajolet, O., Cottrez, F., Magnone, V., Merten, M., Groux, H., Puchelle, E., and Barbry, P. (2005). Live Staphylococcus aureus and bacterial soluble factors induce different transcriptional responses in human airway cells. Physiol Genomics 20, 244-255.

Muir, R.E., and Tan, M.W. (2008). Virulence of Leucobacter chromiireducens subsp. solipictus to Caenorhabditis elegans: characterization of a novel host-pathogen interaction. Appl Environ Microbiol 74, 4185-4198.

Naresh, N.U., and Haynes, C.M. (2019). Signaling and Regulation of the Mitochondrial Unfolded Protein Response. Cold Spring Harb Perspect Biol 11.

Nicholas, H.R., and Hodgkin, J. (2004). The ERK MAP kinase cascade mediates tail swelling and a protective response to rectal infection in C. elegans. Curr Biol 14, 1256-1261.

Nichols, F.C., Yao, X., Bajrami, B., Downes, J., Finegold, S.M., Knee, E., Gallagher, J.J., Housley, W.J., and Clark, R.B. (2011). Phosphorylated dihydroceramides from common human bacteria are recovered in human tissues. PLoS One 6, e16771.

Nillegoda, N.B., Wentink, A.S., and Bukau, B. (2018). Protein Disaggregation in Multicellular Organisms. Trends Biochem Sci 43, 285-300.

O'Brien, D., Jones, L.M., Good, S., Miles, J., Vijayabaskar, M.S., Aston, R., Smith, C.E., Westhead, D.R., and van Oosten-Hawle, P. (2018). A PQM-1-Mediated Response Triggers Transcellular Chaperone Signaling and Regulates Organismal Proteostasis. Cell Rep 23, 3905-3919.

O'Donnell, M.P., Fox, B.W., Chao, P.-H., Schroeder, F.C., and Sengupta, P. (2020). A neurotransmitter produced by gut bacteria modulates host sensory behaviour. Nature.

O'Rourke, D., Baban, D., Demidova, M., Mott, R., and Hodgkin, J. (2006). Genomic clusters, putative pathogen recognition molecules, and antimicrobial genes are induced by infection of $C$. elegans with $M$. nematophilum. Genome Res 16, 1005-1016.

Olaitan, A.O., and Aballay, A. (2018). Non-proteolytic activity of 19S proteasome subunit RPT-6 regulates GATA transcription during response to infection. PLoS Genet 14, e1007693.

Osman, G.A., Fasseas, M.K., Koneru, S.L., Essmann, C.L., Kyrou, K., Srinivasan, M.A., Zhang, G., Sarkies, P., Felix, M.A., and Barkoulas, M. (2018). Natural Infection of C. elegans by an Oomycete Reveals a New PathogenSpecific Immune Response. Curr Biol 28, 640-648 e645.

Otarigho, B., and Aballay, A. (2020). Cholesterol Regulates Innate Immunity via Nuclear Hormone Receptor NHR-8. iScience 23, 101068.

Panek, J., Gang, S.S., Reddy, K.C., Luallen, R.J., Fulzele, A., Bennett, E.J., and Troemel, E.R. (2020). A cullinRING ubiquitin ligase promotes thermotolerance as part of the intracellular pathogen response in. Proc Natl Acad Sci U S A 117, 7950-7960.

Paro, S., Imler, J.L., and Meignin, C. (2015). Sensing viral RNAs by Dicer/RIG-I like ATPases across species. Current Opinion in Immunology 32, 106-113.

Parsons, L.M., and Cipollo, J. (2014). Oral ingestion of Microbacterium nematophilum leads to anal-region infection in Caenorhabditis elegans. Microbes Infect 16, 356-361.

Pees, B., Kloock, A., Nakad, R., Barbosa, C., and Dierking, K. (2017). Enhanced behavioral immune defenses in a C. elegans C-type lectin-like domain gene mutant. Dev Comp Immunol 74, 237-242.

Pellegrino, M.W., Nargund, A.M., Kirienko, N.V., Gillis, R., Fiorese, C.J., and Haynes, C.M. (2014). Mitochondrial UPR-regulated innate immunity provides resistance to pathogen infection. Nature 516, 414-417.

Polanowska, J., Chen, J.X., Soule, J., Omi, S., Belougne, J., Taffoni, C., Pujol, N., Selbach, M., Zugasti, O., and Ewbank, J.J. (2018). Evolutionary plasticity in the innate immune function of Akirin. PLoS Genet 14, e1007494.

Pomatto, L.C.D., and Davies, K.J.A. (2018). Adaptive homeostasis and the free radical theory of ageing. Free Radic Biol Med 124, 420-430.

Powell, J.R., Kim, D.H., and Ausubel, F.M. (2009). The G protein-coupled receptor FSHR-1 is required for the Caenorhabditis elegans innate immune response. Proc Natl Acad Sci U S A 106, 2782-2787.

Pradel, E., Zhang, Y., Pujol, N., Matsuyama, T., Bargmann, C.I., and Ewbank, J.J. (2007). Detection and avoidance of a natural product from the pathogenic bacterium Serratia marcescens by Caenorhabditis elegans. Proc Natl Acad Sci U S A 104, 2295-2300.

Prahlad, V., Cornelius, T., and Morimoto, R.I. (2008). Regulation of the cellular heat shock response in Caenorhabditis elegans by thermosensory neurons. Science 320, 811-814.

Pujol, N., Cypowyj, S., Ziegler, K., Millet, A., Astrain, A., Goncharov, A., Jin, Y., Chisholm, A.D., and Ewbank, J.J. (2008a). Distinct innate immune responses to infection and wounding in the $C$. elegans epidermis. Curr Biol 18, 481-489.

Pujol, N., Davis, P.A., and Ewbank, J.J. (2012). The Origin and Function of Anti-Fungal Peptides in C. elegans: Open Questions. Front Immunol 3, 237. 
Pujol, N., Link, E.M., Liu, L.X., Kurz, C.L., Alloing, G., Tan, M.W., Ray, K.P., Solari, R., Johnson, C.D., and Ewbank, J.J. (2001). A reverse genetic analysis of components of the Toll signalling pathway in Caenorhabditis elegans. Curr Biol 11, 809-821.

Pujol, N., Zugasti, O., Wong, D., Couillault, C., Kurz, C.L., Schulenburg, H., and Ewbank, J.J. (2008b). Antifungal innate immunity in $C$. elegans is enhanced by evolutionary diversification of antimicrobial peptides. PLoS Pathog 4, e1000105.

Pukkila-Worley, R. (2016). Surveillance Immunity: An Emerging Paradigm of Innate Defense Activation in Caenorhabditis elegans. PLoS Pathog 12, e1005795.

Pukkila-Worley, R., Ausubel, F.M., and Mylonakis, E. (2011). Candida albicans infection of Caenorhabditis elegans induces antifungal immune defenses. PLoS Pathog 7, e1002074.

Radhakrishnan, S.K., den Besten, W., and Deshaies, R.J. (2014). p97-dependent retrotranslocation and proteolytic processing govern formation of active Nrf1 upon proteasome inhibition. Elife 3, e01856.

Rangan, K.J., Pedicord, V.A., Wang, Y.C., Kim, B., Lu, Y., Shaham, S., Mucida, D., and Hang, H.C. (2016). A secreted bacterial peptidoglycan hydrolase enhances tolerance to enteric pathogens. Science 353, 1434-1437.

Reboul, J., and Ewbank, J.J. (2016). GPCRs in invertebrate innate immunity. Biochem Pharmacol.

Reddy, K.C., Dror, T., Sowa, J.N., Panek, J., Chen, K., Lim, E.S., Wang, D., and Troemel, E.R. (2017). An Intracellular Pathogen Response Pathway Promotes Proteostasis in C. elegans. Curr Biol 27, 3544-3553 e3545.

Reddy, K.C., Dror, T., Underwood, R.S., Osman, G.A., Elder, C.R., Desjardins, C.A., Cuomo, C.A., Barkoulas, M., and Troemel, E.R. (2019). Antagonistic paralogs control a switch between growth and pathogen resistance in C. elegans. PLoS Pathog 15, e1007528.

Reddy, K.C., Dunbar, T.L., Nargund, A.M., Haynes, C.M., and Troemel, E.R. (2016). The C. elegans CCAATEnhancer-Binding Protein Gamma Is Required for Surveillance Immunity. Cell Rep 14, 1581-1589.

Richardson, C.E., Kooistra, T., and Kim, D.H. (2010). An essential role for XBP-1 in host protection against immune activation in C. elegans. Nature 463, 1092-1095.

Rolland, S.G., Schneid, S., Schwarz, M., Rackles, E., Fischer, C., Haeussler, S., Regmi, S.G., Yeroslaviz, A., Habermann, B., Mokranjac, D., et al. (2019). Compromised Mitochondrial Protein Import Acts as a Signal for UPR. Cell Rep 28, 1659-1669.e1655.

Romanelli-Cedrez, L., Carrera, I., Otero, L., Miranda-Vizuete, A., Mariotti, M., Alkema, M.J., and Salinas, G. (2017). Selenoprotein T is required for pathogenic bacteria avoidance in Caenorhabditis elegans. Free Radic Biol Med 108, 174-182.

Rouger, V., Bordet, G., Couillault, C., Monneret, S., Mailfert, S., Ewbank, J.J., Pujol, N., and Marguet, D. (2014). Independent Synchronized Control and Visualization of Interactions between Living Cells and Organisms. Biophysical journal 106, 2096-2104.

Royaee, A.R., Jong, L., Mendis, C., Das, R., Jett, M., and Yang, D.C.H. (2006). Cholera toxin induced novel genes in human lymphocytes and monocytes. Mol Immunol 43, 1267-1274.

Rua, R., and Pujol, N. (2020). IL-17: good fear no tears. Nat Immunol 21, 1315-1316.

Samuel, B.S., Rowedder, H., Braendle, C., Felix, M.A., and Ruvkun, G. (2016). Caenorhabditis elegans responses to bacteria from its natural habitats. Proc Natl Acad Sci U S A 113, E3941-3949.

Sandoval, L.E., Jiang, H., and Wang, D. (2019). The Dietary Restriction-Like Gene drl-1, Which Encodes a Putative Serine/Threonine Kinase, Is Essential for Orsay Virus Infection in Caenorhabditis elegans. J Virol 93.

Schnupf, P., and Portnoy, D.A. (2007). Listeriolysin O: a phagosome-specific lysin. Microbes Infect 9, 11761187.

Schreiner, W.P., Pagliuso, D.C., Garrigues, J.M., Chen, J.S., Aalto, A.P., and Pasquinelli, A.E. (2019). Remodeling of the Caenorhabditis elegans non-coding RNA transcriptome by heat shock. Nucleic Acids Res 47, 9829-9841.

Schulenburg, H., and Félix, M.-A. (2017). The Natural Biotic Environment of Caenorhabditis elegans. Genetics 206, 55-86.

Segref, A., Kevei, E., Pokrzywa, W., Schmeisser, K., Mansfeld, J., Livnat-Levanon, N., Ensenauer, R., Glickman, M.H., Ristow, M., and Hoppe, T. (2014). Pathogenesis of human mitochondrial diseases is modulated by reduced activity of the ubiquitin/proteasome system. Cell Metab 19, 642-652.

Sellegounder, D., Yuan, C.H., Wibisono, P., Liu, Y., and Sun, J. (2018). Octopaminergic Signaling Mediates Neural Regulation of Innate Immunity in Caenorhabditis elegans. mBio 9.

Seong, S.Y., and Matzinger, P. (2004). Hydrophobicity: an ancient damage-associated molecular pattern that initiates innate immune responses. Nat Rev Immunol 4, 469-478.

Shenkman, M., and Lederkremer, G.Z. (2019). Compartmentalization and Selective Tagging for Disposal of Misfolded Glycoproteins. Trends Biochem Sci 44, 827-836. 
Shivers, R.P., Youngman, M.J., and Kim, D.H. (2008). Transcriptional responses to pathogens in Caenorhabditis elegans. Curr Opin Microbiol 11, 251-256.

Shpilka, T., and Haynes, C.M. (2018). The mitochondrial UPR: mechanisms, physiological functions and implications in ageing. Nat Rev Mol Cell Biol 19, 109-120.

Shtonda, B.B., and Avery, L. (2006). Dietary choice behavior in Caenorhabditis elegans. J Exp Biol 209, 89102.

Siddique, M.M., Li, Y., Chaurasia, B., Kaddai, V.A., and Summers, S.A. (2015). Dihydroceramides: From Bit Players to Lead Actors. J Biol Chem 290, 15371-15379.

Singh, J., and Aballay, A. (2019). Microbial Colonization Activates an Immune Fight-and-Flight Response via Neuroendocrine Signaling. Dev Cell 49, 89-99 e84.

Singh, J., and Aballay, A. (2020). Neural control of behavioral and molecular defenses in C. elegans.

Current Opinion in Neurobiology 62, 34-40.

Singh, V., and Aballay, A. (2006). Heat-shock transcription factor (HSF)-1 pathway required for Caenorhabditis elegans immunity. Proc Natl Acad Sci U S A 103, 13092-13097.

Singh, V., and Aballay, A. (2012). Endoplasmic reticulum stress pathway required for immune homeostasis is neurally controlled by arrestin-1. J Biol Chem 287, 33191-33197.

Sinha, N.K., Iwasa, J., Shen, P.S., and Bass, B.L. (2018). Dicer uses distinct modules for recognizing dsRNA termini. Science 359, 329-+.

Sinner, M.P., Masurat, F., Ewbank, J.J., Pujol, N., and Bringmann, H. (2020). Innate Immunity Promotes Sleep through Epidermal Antimicrobial Peptides. Current Biology.

Sowa, J.N., Jiang, H., Somasundaram, L., Tecle, E., Xu, G., Wang, D., and Troemel, E.R. (2020). The Caenorhabditis elegans RIG-I Homolog DRH-1 Mediates the Intracellular Pathogen Response upon Viral Infection. J Virol 94.

Sun, J., Singh, V., Kajino-Sakamoto, R., and Aballay, A. (2011). Neuronal GPCR controls innate immunity by regulating noncanonical unfolded protein response genes. Science 332, 729-732.

Szumowski, S.C., Botts, M.R., Popovich, J.J., Smelkinson, M.G., and Troemel, E.R. (2014). The small GTPase RAB-11 directs polarized exocytosis of the intracellular pathogen $N$. parisii for fecal-oral transmission from $C$. elegans. P Natl Acad Sci USA 111, 8215-8220.

Taffoni, C., Omi, S., Huber, C., Mailfert, S., Fallet, M., Rupprecht, J.F., Ewbank, J.J., and Pujol, N. (2020). Microtubule plus-end dynamics link wound repair to the innate immune response. Elife 9.

Taffoni, C., and Pujol, N. (2015). Mechanisms of innate immunity in C. elegans epidermis. Tissue Barriers 3, e1078432.

Tang, D., Kang, R., Coyne, C.B., Zeh, H.J., and Lotze, M.T. (2012). PAMPs and DAMPs: signal Os that spur autophagy and immunity. Immunol Rev 249, 158-175.

Tang, H., and Pang, S. (2016). Proline Catabolism Modulates Innate Immunity in Caenorhabditis elegans. Cell Rep 17, 2837-2844.

Tanguy, M., Veron, L., Stempor, P., Ahringer, J., Sarkies, P., and Miska, E.A. (2017). An Alternative STAT Signaling Pathway Acts in Viral Immunity in Caenorhabditis elegans. MBio 8.

Tartey, S., Matsushita, K., Imamura, T., Wakabayashi, A., Ori, D., Mino, T., and Takeuchi, O. (2015). Essential Function for the Nuclear Protein Akirin2 in B Cell Activation and Humoral Immune Responses. Journal of immunology.

Taylor, R.C., Berendzen, K.M., and Dillin, A. (2014). Systemic stress signalling: understanding the cell nonautonomous control of proteostasis. Nat Rev Mol Cell Biol 15, 211-217.

Taylor, R.C., and Dillin, A. (2013). XBP-1 is a cell-nonautonomous regulator of stress resistance and longevity. Cell 153, 1435-1447.

Thibault, G., Shui, G., Kim, W., McAlister, G.C., Ismail, N., Gygi, S.P., Wenk, M.R., and Ng, D.T.W. (2012). The membrane stress response buffers lethal effects of lipid disequilibrium by reprogramming the protein homeostasis network. Mol Cell 48, 16-27.

Tiku, V., Kew, C., Mehrotra, P., Ganesan, R., Robinson, N., and Antebi, A. (2018). Nucleolar fibrillarin is an evolutionarily conserved regulator of bacterial pathogen resistance. Nat Commun 9, 3607.

Tiku, V., Tan, M.-W., and Dikic, I. (2020). Mitochondrial Functions in Infection and Immunity. Trends Cell Biol 30, 263-275.

Tiller, G.R., and Garsin, D.A. (2014). The SKPO-1 Peroxidase Functions in the Hypodermis to Protect Caenorhabditis elegans From Bacterial Infection. Genetics 197, 515-526.

Tillman, E.J., Richardson, C.E., Cattie, D.J., Reddy, K.C., Lehrbach, N.J., Droste, R., Ruvkun, G., and Kim, D.H. (2018). Endoplasmic Reticulum Homeostasis Is Modulated by the Forkhead Transcription Factor FKH-9 During Infection of Caenorhabditis elegans. Genetics 210, 1329-1337. 
Tjahjono, E., and Kirienko, N.V. (2017). A conserved mitochondrial surveillance pathway is required for defense against Pseudomonas aeruginosa. PLoS Genet 13, e1006876.

Tjahjono, E., McAnena, A.P., and Kirienko, N.V. (2020). The evolutionarily conserved ESRE stress response network is activated by ROS and mitochondrial damage. BMC Biol 18, 74.

Tong, A., Lynn, G., Ngo, V., Wong, D., Moseley, S.L., Ewbank, J.J., Goncharov, A., Wu, Y.C., Pujol, N., and Chisholm, A.D. (2009). Negative regulation of Caenorhabditis elegans epidermal damage responses by deathassociated protein kinase. Proc Natl Acad Sci U S A 106, 1457-1461.

Tran, A., Tang, A., O'Loughlin, C.T., Balistreri, A., Chang, E., Coto Villa, D., Li, J., Varshney, A., Jimenez, V., Pyle, J., et al. (2017). C. elegans avoids toxin-producing Streptomyces using a seven transmembrane domain chemosensory receptor. Elife 6.

Troemel, E.R. (2016). Host-Microsporidia Interactions in Caenorhabditis elegans, a Model Nematode Host. Microbiol Spectr 4.

Troemel, E.R., Chu, S.W., Reinke, V., Lee, S.S., Ausubel, F.M., and Kim, D.H. (2006). p38 MAPK regulates expression of immune response genes and contributes to longevity in C. elegans. PLoS Genet 2, e183.

Turner, M.J., Cox, J.K., Spellman, A.C., Stahl, C., and Bavari, S. (2020). Avoidance behavior independent of innate-immune signaling seen in Caenorhabditis elegans challenged with Bacillus anthracis. Dev Comp Immunol 102, 103453.

van Oosten-Hawle, P., and Morimoto, R.I. (2014). Transcellular chaperone signaling: an organismal strategy for integrated cell stress responses. J Exp Biol 217, 129-136.

van Oosten-Hawle, P., Porter, R.S., and Morimoto, R.I. (2013). Regulation of organismal proteostasis by transcellular chaperone signaling. Cell 153, 1366-1378.

Vihervaara, A., Duarte, F.M., and Lis, J.T. (2018). Molecular mechanisms driving transcriptional stress responses. Nat Rev Genet 19, 385-397.

Visvikis, O., Ihuegbu, N., Labed, S.A., Luhachack, L.G., Alves, A.M., Wollenberg, A.C., Stuart, L.M., Stormo, G.D., and Irazoqui, J.E. (2014). Innate Host Defense Requires TFEB-Mediated Transcription of Cytoprotective and Antimicrobial Genes. Immunity 40, 896-909.

Wan, L., Lin, J., Du, H., Zhang, Y., Bravo, A., Soberón, M., Sun, M., and Peng, D. (2019). Bacillus thuringiensis targets the host intestinal epithelial junctions for successful infection of Caenorhabditis elegans. Environ Microbiol 21, 1086-1098.

Wang, S., Gao, K., and Liu, Y. (2018). UPR coordinates immunity to maintain mitochondrial homeostasis and animal fitness. Mitochondrion 41, 9-13.

Wang, W., and Chan, J.Y. (2006). Nrf1 is targeted to the endoplasmic reticulum membrane by an Nterminal transmembrane domain. Inhibition of nuclear translocation and transacting function. J Biol Chem 281, 19676-19687.

Wani, K.A., Goswamy, D., and Irazoqui, J.E. (2020). Nervous system control of intestinal host defense in $C$. elegans. Current Opinion in Neurobiology 62, 1-9.

Weaver, B.P., Weaver, Y.M., Omi, S., Yuan, W., Ewbank, J.J., and Han, M. (2020). Non-Canonical Caspase Activity Antagonizes p38 MAPK Stress-Priming Function to Support Development. Dev Cell 53, 358-369.e356.

Williams, A.B., Heider, F., Messling, J.E., Rieckher, M., Bloch, W., and Schumacher, B. (2019). Restoration of Proteostasis in the Endoplasmic Reticulum Reverses an Inflammation-Like Response to Cytoplasmic DNA in Caenorhabditis elegans. Genetics 212, 1259-1278.

Xu, S., and Chisholm, A.D. (2011). A Galpha(q)-Ca(2+) signaling pathway promotes actin-mediated epidermal wound closure in C. elegans. Curr Biol 21, 1960-1967.

Yoo, S.-M., and Jung, Y.-K. (2018). A Molecular Approach to Mitophagy and Mitochondrial Dynamics. Mol Cells 41, 18-26.

Yook, K., and Hodgkin, J. (2007). Mos1 mutagenesis reveals a diversity of mechanisms affecting response of Caenorhabditis elegans to the bacterial pathogen Microbacterium nematophilum. Genetics 175, 681-697.

Zarate-Potes, A., Yang, W., Pees, B., Schalkowski, R., Segler, P., Andresen, B., Haase, D., Nakad, R., Rosenstiel, P., Tetreau, G., et al. (2020). The C. elegans GATA transcription factor elt-2 mediates distinct transcriptional responses and opposite infection outcomes towards different Bacillus thuringiensis strains. PLoS Pathog 16, e1008826.

Zhang, G., Sachse, M., Prevost, M.C., Luallen, R.J., Troemel, E.R., and Felix, M.A. (2016). A Large Collection of Novel Nematode-Infecting Microsporidia and Their Diverse Interactions with Caenorhabditis elegans and Other Related Nematodes. PLoS Pathog 12, e1006093.

Zhang, J., Holdorf, A.D., and Walhout, A.J. (2017). C. elegans and its bacterial diet as a model for systemslevel understanding of host-microbiota interactions. Curr Opin Biotechnol 46, 74-80. 
Zhang, Q., Wu, X., Chen, P., Liu, L., Xin, N., Tian, Y., and Dillin, A. (2018). The Mitochondrial Unfolded Protein Response Is Mediated Cell-Non-autonomously by Retromer-Dependent Wnt Signaling. Cell 174, 870883.e817.

Ziegler, K., Kurz, C.L., Cypowyj, S., Couillault, C., Pophillat, M., Pujol, N., and Ewbank, J.J. (2009). Antifungal innate immunity in C. elegans: PKCdelta links G protein signaling and a conserved p38 MAPK cascade. Cell Host Microbe 5, 341-352.

Zimmermann, J., Obeng, N., Yang, W., Pees, B., Petersen, C., Waschina, S., Kissoyan, K.A., Aidley, J., Hoeppner, M.P., Bunk, B., et al. (2020). The functional repertoire contained within the native microbiota of the model nematode Caenorhabditis elegans. ISME J 14, 26-38.

Zugasti, O., Bose, N., Squiban, B., Belougne, J., Kurz, C.L., Schroeder, F.C., Pujol, N., and Ewbank, J.J. (2014). Activation of a $\mathrm{G}$ protein-coupled receptor by its endogenous ligand triggers the innate immune response of Caenorhabditis elegans. Nat Immunol 15, 833-838.

Zugasti, O., and Ewbank, J.J. (2009). Neuroimmune regulation of antimicrobial peptide expression by a noncanonical TGF-beta signaling pathway in Caenorhabditis elegans epidermis. Nat Immunol 10, 249-256.

Zugasti, O., Thakur, N., Belougne, J., Squiban, B., Kurz, C.L., Soule, J., Omi, S., Tichit, L., Pujol, N., and Ewbank, J.J. (2016). A quantitative genome-wide RNAi screen in C. elegans for antifungal innate immunity genes. BMC Biol 14, 35. 


\section{FIGURE 1}
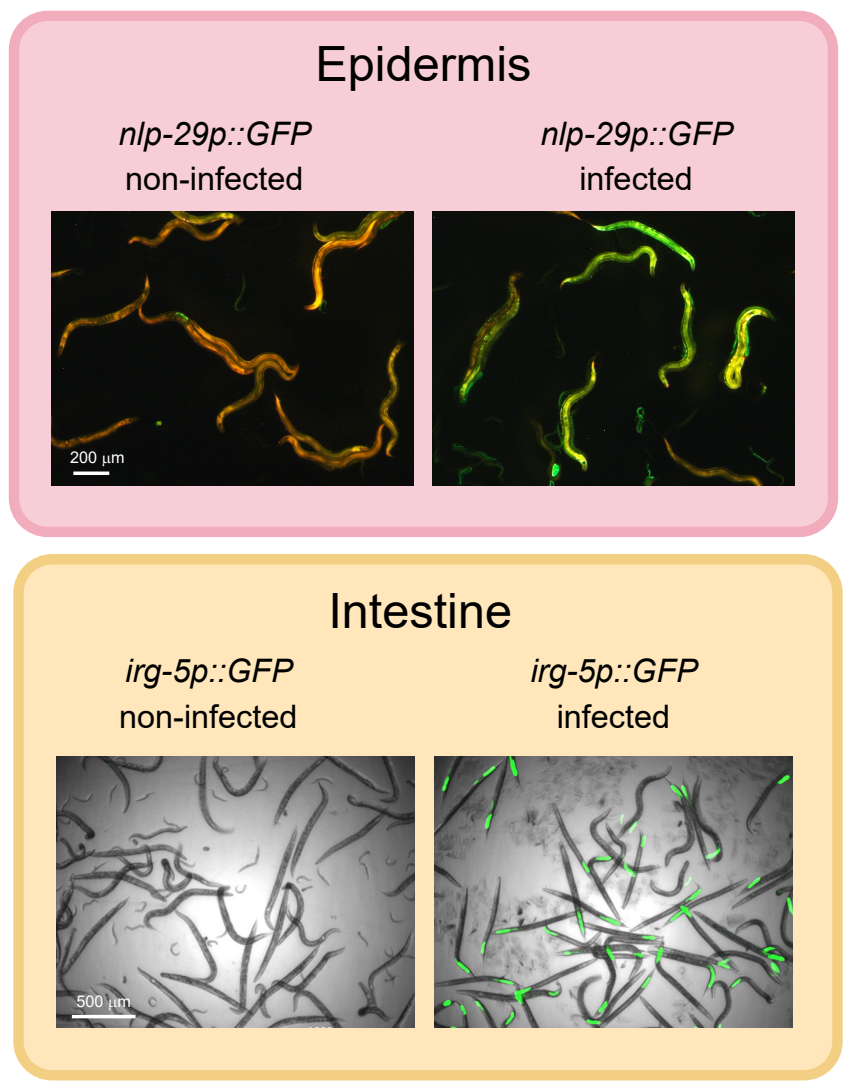

Fig. 1 Cell-autonomous responses to infection. Examples of two canonical immune responses to infection, in the epidermis following infection by the fungus

$D$. coniospora (Pujol et al., 2008), and in the intestine by the bacterium $P$. aeruginosa (Troemel et al., 2006). Defence gene induction is observed with the transcriptional reporters, nlp-29p::GFP (top, epidermis) and irg-5p::GFP (bottom, intestine), the worms are visualized with a constitutive epidermal red fluorescent reporter (top) and in bright field (bottom). 


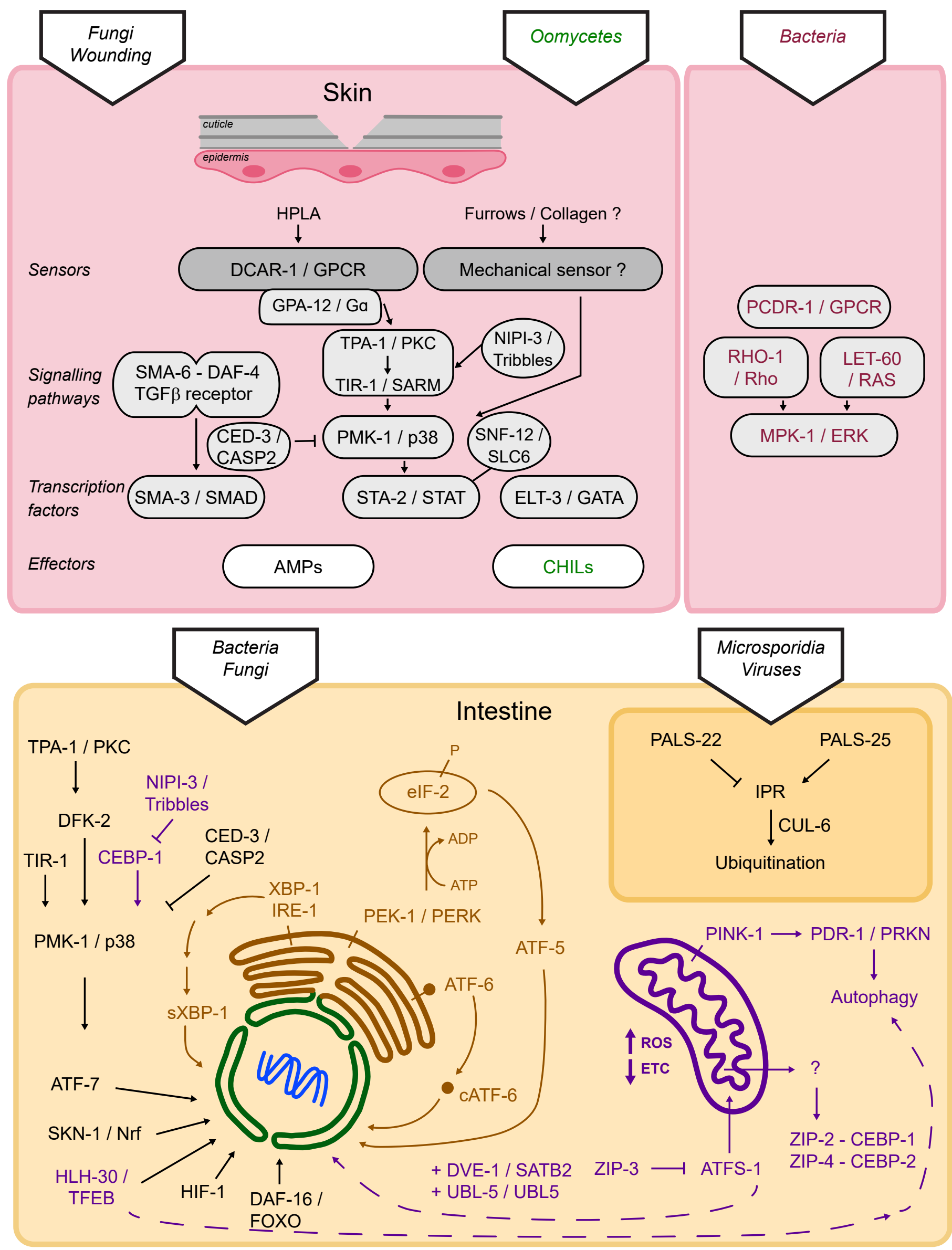

Fig. 2 Cell-autonomous regulation of innate immunity in $C$. elegans. Depending on the site of infection and on the pathogen, innate immunity is regulated through diverse pathways and effectors, see text for details. 
FIGURE 3

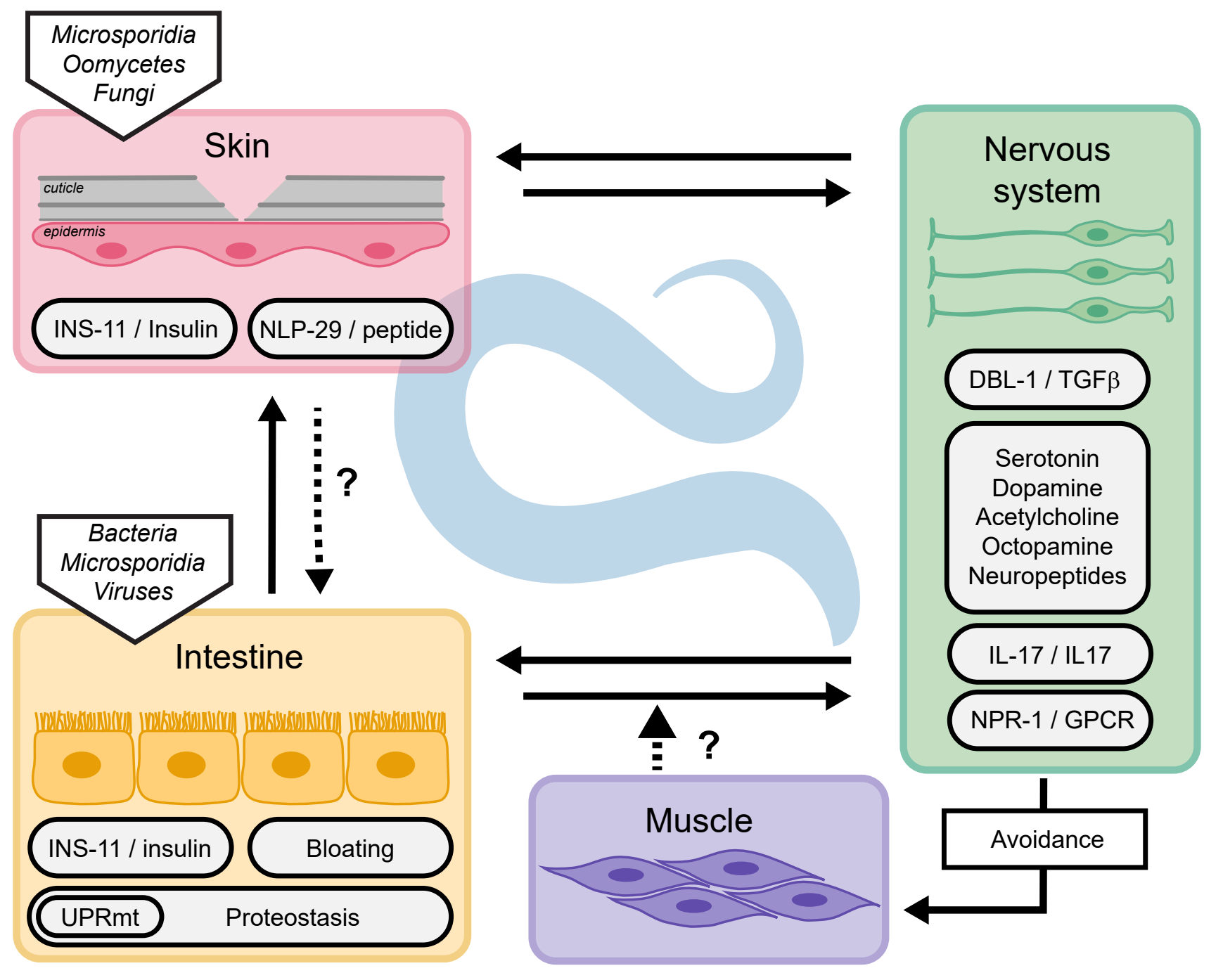

Fig. 3 Cross-tissue regulation of innate immunity in C. elegans. Innate immunity is regulated cell non-autonomously through direct or indirect communication between tissues. 